\title{
The use of minimally invasive biomarkers for the diagnosis and prognosis of hepatocellular carcinoma
}

\author{
Lucas Trevisan França de Lima ${ }^{1,3}$, Daniel Broszczak ${ }^{1}$, Xi Zhang ${ }^{1}$, Kim Bridle ${ }^{2,3}$, Darrell \\ Crawford $^{2,3}$, Chamindie Punyadeera ${ }^{1 *}$.
}

1. Institute of Health \& Biomedical Innovation, School of Biomedical Sciences, Queensland University of Technology, Kelvin Grove Campus, QLD, Australia

2. The University of Queensland, Faculty of Medicine, Herston, QLD, Australia

3. Gallipoli Medical Research Foundation, Greenslopes Private Hospital, Greenslopes, QLD, Australia

Correspondence

Associate Professor Chamindie Punyadeera

Address: Saliva and Liquid Biopsy Translational Laboratory, The School of Biomedical Sciences, Room 603D, Institute of Health and Biomedical Innovation, Queensland University of Technology, 60 Musk Avenue, Kelvin Grove, QLD 4059, Australia.

Email: chamindie.punyadeera@qut.edu.au

\begin{abstract}
Hepatocellular carcinoma (HCC) is a common cause of cancer-related deaths worldwide. Despite advances in systemic therapies, patient survival remains low due to late diagnosis and frequent underlying liver diseases. HCC diagnosis generally relies on imaging and liver tissue biopsy. Liver biopsy presents limitations because it is invasive, potentially risky for patients and it frequently misrepresents tumour heterogeneity. Recently, liquid biopsy has emerged as a way to monitor cancer progression in a non-invasive manner. Tumours shed content into the bloodstream, such as circulating tumour cells (CTCS), circulating nucleic acids, extracellular vesicles and proteins, that can be isolated from biological fluids of patients with HCC. These biomarkers provide knowledge regarding the genetic landscape of tumours and might be used for diagnostic or prognostic purposes. In this review, we summarize recent literature on circulating biomarkers for HCC, namely CTCs, circulating tumour DNA (ctDNA), RNA, extracellular vesicles and proteins, and their clinical relevance in HCC.
\end{abstract}

Keywords: liquid biopsy; circulating tumor cells (CTCs); circulating tumor DNA (ctDNA); hepatocellular carcinoma; biomarker, liver cancer. 


\section{INTRODUCTION / BACKGROUND}

Hepatocellular carcinoma (HCC) corresponds to $>80 \%$ of primary liver cancers worldwide [1]. HCC is the $3^{\text {rd }}$ leading cause of cancer-related death in the world [2], and in contrast to other types of cancer, the disease burden of liver cancer has been increasing over the last decades [3]. HCC occurrence is highly variable across' different geographic regions, ethnic groups and between men and women. The majority of HCC cases develop on the background of chronic liver diseases, and are usually associated with advanced fibrosis or hepatic cirrhosis. Although nearly $80 \%$ of HCC cases are related to chronic viral hepatitis [4], other liver diseases such as non-alcoholic fatty liver disease (NAFLD) and nonalcoholic steatohepatitis (NASH) associated with metabolic syndrome and obesity are the most relevant underlying conditions in the remaining cases. There are reports of $\mathrm{HCC}$ without cirrhosis in a significant proportion of those cases $[5,6]$. The remarkably poor outcome of patients with HCC (5-year survival rate of $5 \%$ ) is related to the difficulty in surveillance in at risk populations and the lack of widely available diagnostic tools for early detection, resulting in patients being diagnosed with advanced non-resectable tumours [7].

On the basis of proteome, gene expression and genome profiling, $\mathrm{HCC}$ cells have been classified into two major groups: a highly-aggressive "proliferative class", which is mainly characterized by the inactivation of TP53, activation of the TGF- $\beta$ pathway and Wnt proliferation signals, positivity of stemness markers and high alpha-fetoprotein (AFP); and a heterogeneous "nonproliferative class" related to CTNNB1 gene and TERT promoter mutations, the maintenance of a hepatocyte-like phenotype and the hypermethylation of CDKN2A and CDH1 [8-10]. Therefore, each subtype presents specific genetic and epigenetic characteristics that determine the patient's prognosis and response to treatment, although a direct translation of these findings into clinical management has not yet been achieved [11].

Currently, surveillance of patients at risk for HCC is the most effective measure to decrease the burden of the disease. Chen et al. implemented a surveillance protocol for HBV surface antigen-positive (HBsAg) individuals $(n=5,581)$ in China, and showed that a six-monthly ultrasound examination and serum $\alpha$-fetoprotein (AFP) level measurement $(20 \mu \mathrm{g} / \mathrm{L}$ cut off) was an effective strategy in the early detection of primary liver tumours in screened patients (29.6\%) when compared to the unscreened group (6.0\%) [12]. However, AFP alone has high false-negative rates (40\%) and lacks sensitivity (49\% 61\%) for detecting the early stages of the disease [13]. Consequently, other biomarkers have been proposed recently, such as des- - -carboxyprothrombin (DCP), glypican-3 (GP3) and Golgi protein 73 (GP73) $[14,15]$. In this context, the use of other circulating biomarkers could facilitate the earlier diagnosis of HCC, better predict patient outcomes, and monitor response to treatment. This review 
aims to summarize recent literature on circulating biomarkers for HCC, with a focus on ctDNA, circulating RNAs, CTCs, proteins and exosomes.

\section{MANAGEMENT OF HCC}

\subsection{Diagnosis}

The diagnosis of HCC is made by imaging and often confirmed using other radiological findings, or less frequently, by tissue biopsy [16]. Recent advances in computed tomography (CT) and magnetic resonance imaging (MRI) have decreased the need for liver biopsy. However, diagnostic accuracy for $<2 \mathrm{~cm}$ tumours by MRI is problematic in the cirrhotic liver, with a lower sensitivity (13-67\%) when compared to $>3 \mathrm{~cm}$ tumours (100\%) $[4,17]$. Therefore, tissue biopsy remains the gold-standard for the detection of liver cancer, despite the risks associated with it including excessive bleeding, vasovagal reaction, and pneumothorax. More importantly, a potential complication after liver biopsy is needle track seeding, which occurs when cancer cells spread along the needle track and reach other sites inside the liver, the peritoneal cavity, abdominal muscles, and the skin [18]. A meta-analysis of 8 studies reported an incidence of $2.7 \%$ of needle track seeding 17 months after biopsy [19]. Another disadvantage of biopsy is the frequent sampling error due to the high heterogeneity of the tumours, which leads to a high rate of false-negative results.

Immunohistochemistry (IHC) techniques may be used to distinguish HCC from premalignant lesions and intrahepatic cholangiocarcinoma [20]. Several markers have been proposed for the diagnosis of HCC using IHC staining of tissue samples, including glypican 3 (GP3), heat shock protein 70 (HSP70) and glutamine synthetase (GS), among which any pair was able to detect HCC with a sensitivity of $40 \%$ and specificity of $100 \%$, with a slight decrease in the false-negative results rate when compared to conventional pathology $[21,22]$.

The use of AFP measurement levels for the diagnosis of HCC has been approved by the Food and Drug Administration (FDA). However, the American Association for the Study of Liver Diseases (ASSLD) and the European Association for the Study of the Liver (EASL) guidelines recommend that diagnosis should rely on typical radiological findings and/or biopsy, whereas circulating biomarkers should be used as a prognostic tool. As a result, candidacy for liver transplantation based on radiological findings alone has been an accepted clinical practice in the last decade [23]. 


\subsection{Treatment}

Considering that liver cancer is predominantly associated with other chronic liver diseases, accurate evaluation of liver function is crucial to determine suitable therapies for each individual. Current therapies for HCC consist of liver transplantation, surgical resection, local ablation, transarterial chemoembolization (TACE) and systemic therapies with tyrosine kinase inhibitors (sorafenib, lenvatinib and regorafenib) $[4,20]$. More recently, immune checkpoint inhibitors have also been used in the treatment of HCC [24].

In general, locoregional embolization associated with chemotherapy is the treatment of choice for unresectable tumours limited to the liver. Doxorubicin- and cisplatin-based TACE increased overallsurvival in comparison to other embolization techniques $[25,26]$. Systemic therapy is reserved for tumours who present extrahepatic spread or have failed at prior local therapy [27]. Sorafenib, and more recently lenvatinib, are the only first-line of systemic drugs approved by the FDA, which have demonstrated similar effects in patients' outcomes with an improvement of $\sim 3$ months in overallsurvival $[28,29]$. Likewise, immune checkpoint inhibitors, mainly anti-program death receptor (PD)-1 monoclonal antibodies (nivolumab and prembolizumab), were shown to increase the overall-survival for a minority of patients (10-20\%) [30, 31]. Also, the use of an anti-vascular endothelial growth factor receptor-2 (VEGFR2) monoclonal antibody (ramucirumab) leads to an improvement in 1.2-1.8 months in overall-survival and 1.2-1.6 months in progression-free survival compared to the placebo group in a phase 3 trial involving patients $(n=292)$ with AFP levels $\geq 400 \mathrm{ng} / \mathrm{mL}$ in 20 countries [32, 33].

More recently in 2020, the FDA approved the administration of atezolizumab plus bevacizumab as the first immunotherapy regimen for the treatment of unreseactable HCC. Atezolizumab is a monoclonal antibody targeting the programmed death-ligand 1 (PD-L1), which is expressed in cancer and immune cells, and blocks T-lymphocyte activation [34]. Bevacizumab is an anti-vascular endothelial growth factor (VEGF) antibody first approved by the FDA as a first-line of treatment for metastatic colorectal cancer [35]. In a phase 3 trial involving 501 treatment-naïve unresectable HCC patients, 336 individuals were treated with atezolizumab plus bevacizumab, and 165 received systemic therapy with sorafenib. Compared to sorafenib, immunotherapy lead to improved overall-survival at 12 months from $54.6 \%$ to $67.2 \%$, and median progression-free survival from 4.3 to 6.8 months, respectively [36]. Notably, the longer time to deterioration of patient-reported quality of life and the lack of unexpected side effects were considered to determine its superiority to chemotherapy. However, Lee and coauthors[37] have shown that similar outcomes are not achieved by using atezolizumab alone, suggesting that the combined effects of both antibodies is important for the efficacy of the treatment. 
Despite advances in the understanding of the molecular pathogenesis of HCC, the lack of molecular signature markers to predict response and monitor HCC treatment hinders the development of novel therapy strategies [38].

\subsection{Prognosis}

Several classification systems for liver cancer have been published in recent years. The OKUDA score, published in 1985, was the first to combine liver function parameters (bilirubin and albumin) and the grade of tumour invasion (more or less than $50 \%$ of liver parenchyma volume)[39]. In 1998, the Cancer of the Liver Italian Program (CLIP) score included other tumour-related parameters such as serum AFP levels, portal vein thrombosis and a more accurate measurement of liver function. The CLIP was reported as the most precise staging system by a number of authors [40, 41]. Nevertheless, the European Association for the Study of the Liver (EASL) and the American Association for the Study of the Liver (AASL) have determined the Barcelona-Clinic Liver Cancer (BCLC) staging system as the reference classification to be used in clinical trials and in day-to-day practice[42]. The BCLC staging system classifies HCC patients into 5 stages (O, A, B, C and D) and suggests appropriate therapies for each stage. For instance, curative resection of the tumour is often feasible for stage 0/A patients, whereas systemic therapy with sorafenib is indicated for stage $C$ individuals [43]. BCLC stage is defined according to the number and size of nodules, the occurrence of extrahepatic metastasis, vascular invasion, liver function (Child-Pugh score), and the overall health status of the individual measured using the Eastern Cooperative Oncology Group (ECOG) score. However, the high heterogeneous characteristics of HCC results in variable outcomes of affected patients. There are reports of a high incidence of early recurrence after curative treatments such as surgery or liver transplantation where the overall-survival rates that can vary from over 60 months to 3 months in advanced stages [38]. Currently, AFP is the only approved biomarker with prognostic values to predict patient outcomes after transplantation, response to locoregional therapies, and survival of advanced AFP-positive HCC patients $[13,42]$. The management of HCC patients is summarized in Figure 1. 
Surveillance

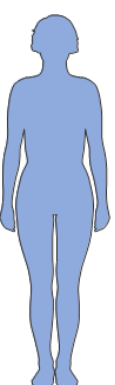

High-risk patient

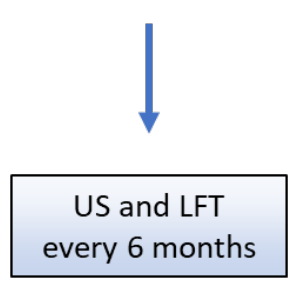

\section{Diagnosis}

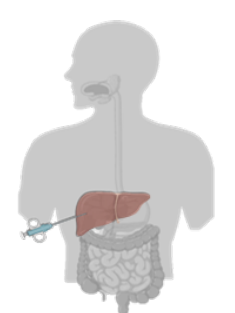

Liver tissue biopsy

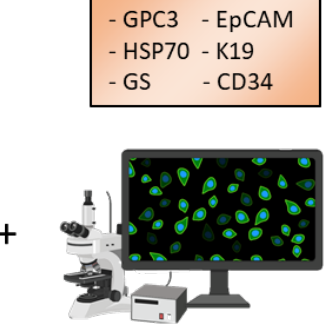

Immunostaining

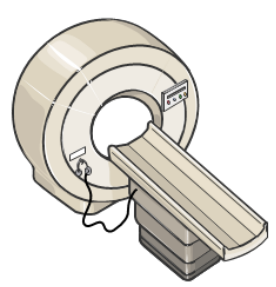

Imaging findings

(CT and/or MRI)

\section{Prognosis}

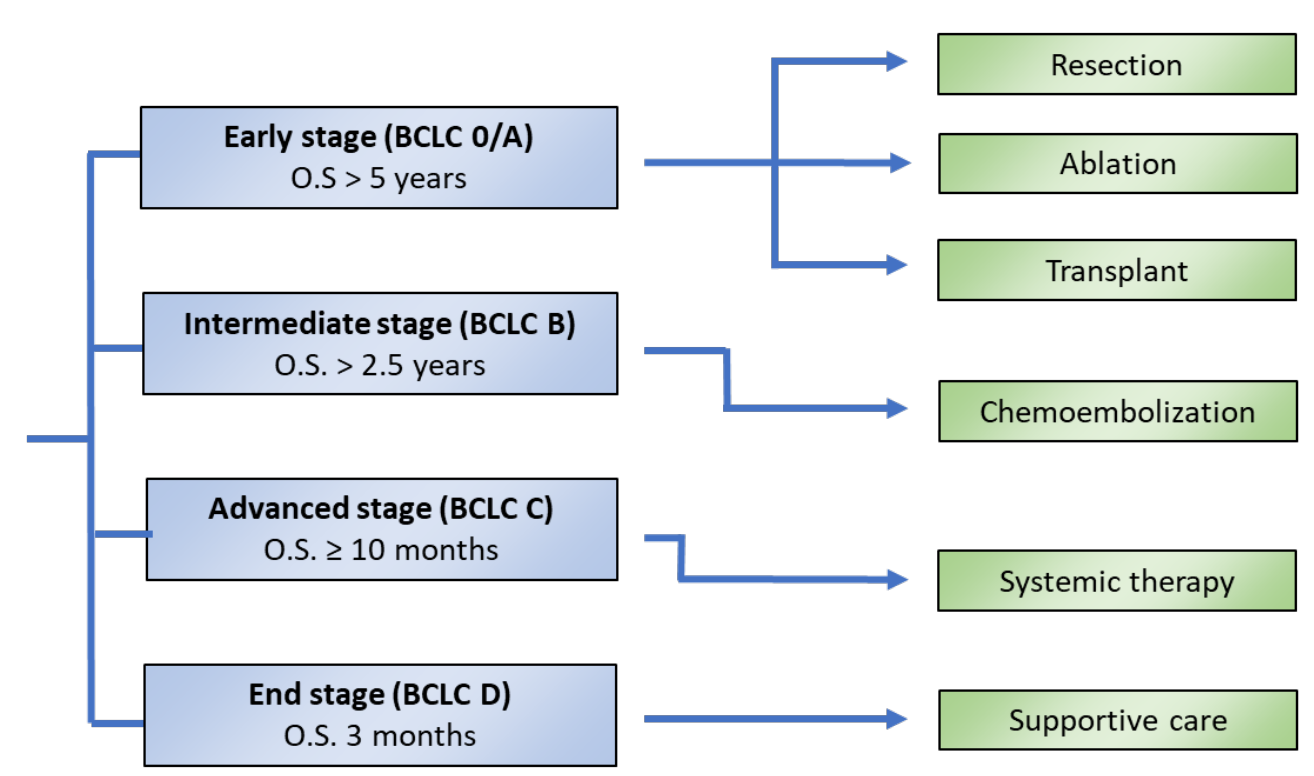

\section{Treatment}

Figure 1. Management of HCC patients according to the European Association for the Study of the Liver (EASL) guidelines (2019). High-risk individuals for HCC include patients with chronic hepatitis B or C virus, alcoholic liver disease, and other diseases that may lead to hepatic cirrhosis. These individuals should undergo an ultrasound (US) examination and a liver function test (LFT) every 6 months. HCC diagnosis is achieved by imaging examination by multiphasic computer tomography (CT) and/or magnetic resonance imaging (MRI), frequently accompanied by liver tissue biopsy. Immunostaining for glypican-3 (GPC3), epithelial cell adhesion molecule (EpCAM), hsp70 chaperone (HSP70), keratin 19 (K19), glutamine synthetase (GS) and neovascularization marker CD34 is performed. Tumour BCLC staging is defined by the size and number of nodules, liver function, portal invasion and extrahepatic metastasis. In early stages, curative options are feasible, such as the surgical removal of the tumour, ablation and liver transplantation. Loco-regional therapies using doxorubicin- or cisplatin-based transarterial chemoembolization (TACE) are indicated for BCLC $B$ stage tumours; whereas advanced stages are treated with systemic therapies with sorafenib (first line) and regorafenib (second line). There is no efficient treatment for BCLC D stage tumours [42]. O.S. - Overall -survival. 


\section{BIOMARKERS FOR HCC}

Early detection is the main challenge in the management of HCC, as currently only $20-30 \%$ of patients are eligible for surgical interventions by the time of diagnosis [44]. During progression, tumours shed content into the bloodstream, and the detection of those by-products in non-solid biological fluids is defined as liquid biopsy [45]. Although liquid biopsies are often carried out using blood, other bodily fluids can also be used, such as saliva, urine and cerebrospinal fluid [46].

For HCC, the EASL highlights the unmet need of developing new tools for early detection or prediction of response to systemic therapy by liquid biopsy [42]. One of the greatest limitations for improving patient care is the lack of biopsy tissue, considering that HCC can be diagnosed based on imaging findings alone. In this context, retrieving information about the tumour using blood or saliva sampling may be a helpful tool to improve HCC management. Compared to traditional biopsies, liquid biopsy presents a number of advantages. First, it is a minimally invasive, relatively faster and cheaper procedure, with fewer risks of complications to patients. Secondly, it is more likely to represent the tumour heterogeneity, considering recent single-cell technologies that provide insight into tumour molecular characteristics from circulating tumour cells, whereas the sampled tissue may not represent the whole tumour in a classical biopsy. Finally, liquid biopsy allows dynamic monitoring of the disease progression over time by repeated sampling [47]. The main circulating biomarkers for HCC are represented in Figure 2. 


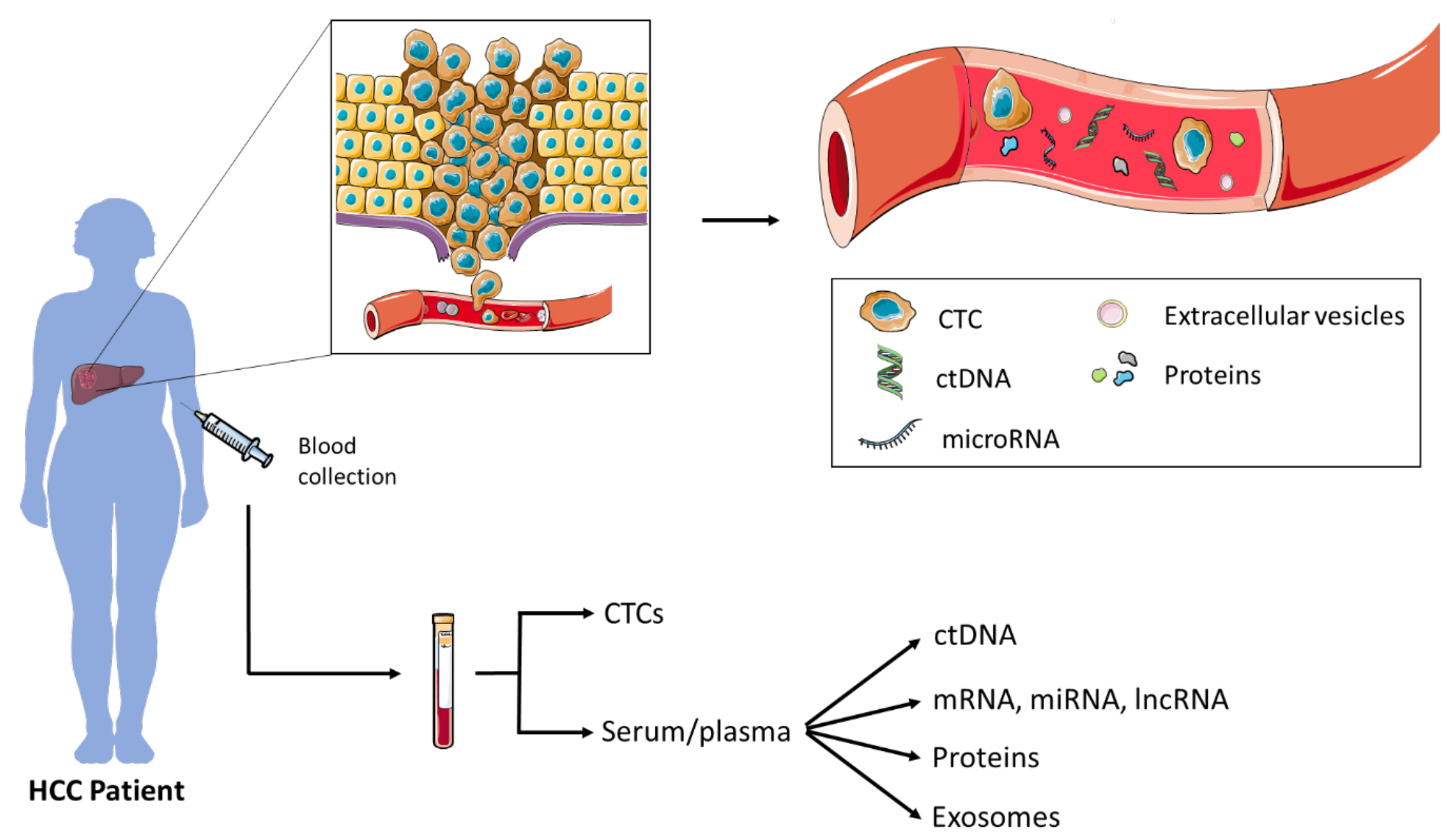

Figure 2. Schematic representation of the circulating biomarkers for HCC. During cancer progression, tumour cells shed content into the bloodstream, which is easily accessible in the peripheral blood of patients. Circulating biomarkers include circulating tumour cells (CTCS) or tumour-derived molecules such as circulating tumour DNA (ctDNA), circulating RNAs, proteins and exosomes. mRNA - messenger RNA, miRNA - microRNA, IncRNA - long non-coding RNA. 


\subsection{Circulating Tumour Nucleic Acid}

The presence of extracellular nucleic acids, particularly DNA and RNA, was first reported in the blood of patients with systemic lupus erythematosus in 1948 [48]. Although circulating RNAs, which include mRNA, long non-coding RNA (IncRNA) and microRNA (miRNA), have shown promising results as targets for liquid biopsy, most studies regarding circulating nucleic acids are focused on cell-free DNA (cfDNA). cfDNA comprises DNA fragments (180-200bp) that are released into the bloodstream by cells undergoing apoptosis or necrosis and rapidly cleared by phagocytes and neighbouring cells [49]. While the cfDNA content in the blood of healthy individuals is usually under $100 \mathrm{ng}$ per $\mathrm{ml}$ of blood, cancer patients often present concentrations $\geq 1000 \mathrm{ng}$ per ml cfDNA [50]. A proportion of the cfDNA directly derived from tumour cells is further classified as circulating tumour DNA (ctDNA). In principle, ctDNA carries tumour-specific mutations and offers the possibility to obtain genetic information on the tumour in a non-invasive manner. ctDNA levels primarily depend on tumour burden, proliferation status and tumour type [44].

\subsection{1 ctDNA in hepatocellular carcinoma}

The use of ctDNA in HCC diagnosis is particularly interesting considering liver cancers, unlike other types of cancer, can be diagnosed without a biopsy, therefore genetic characterization of tumours is scarce [44]. Changes of plasma ctDNA can be evaluated quantitatively by measuring the total ctDNA levels in peripheral blood as well as by using a qualitative approach to identify HCC-related DNA aberrations [51].

Huang et al. [52] conducted a study in which cfDNA in plasma samples collected from 72 patients with HCC was compared to samples from 37 hepatic cirrhosis patients and 41 healthy volunteers using quantitative PCR. HCC patients had higher cfDNA levels (173 ng/mL) when compared to cirrhotic $(46 \mathrm{ng} / \mathrm{mL})$ and healthy individuals $(9 \mathrm{ng} / \mathrm{mL})$, with a positive correlation between circulating tumour DNA concentrations and tumour size, vascular invasion and metastasis. Increased cfDNA levels has also been linked to poor overall-survival rates [53], resistance to systemic therapy with sorafenib [54], and decreased response to radiation therapy [55].

Recent studies report that the number of somatic mutations detected in plasma ctDNA of HCC patients reflect the burden of the primary tumour. In a treatment-naive cohort of HCC patients with metastatic disease and tumours $>5 \mathrm{~cm}$, at least one gene alteration was detected in $86 \%$ ( $n=26 / 30$ ) of paired plasma cfDNA and tissue biopsy samples [56]. Using a 68-gene NGS panel, Ikeda et al. [57] reported somatic alterations in plasma ctDNA samples from 12 out of the 14 patients evaluated in the 
study. The most common single-nucleotide mutations were observed in TP53 (57\%) and CTNNB1 (29\%) genes, whereas amplifications were reported in CDK6 (14\%), EGFR (14\%) and MYC (14\%) [57]. Similarly, in a 354-gene panel analysis performed by An et al.[58], TP53 was also reported with the highest mutation rate (50\%) in plasma ctDNA and paired liver tissue biopsy. This study demonstrated a poor disease-free survival (DFS) of patients with detectable circulating ctDNA mutations after surgery when compared to those in which mutations were not detected (17.5 months vs. 6.7 months, respectively). The authors suggest that ctDNA mutation panels can be used to classify tumours regarding their proliferative status such as Wht pathway activation. In contrast, the frequency of mutations varies significantly in different cohorts, with the chromatin remodelling gene ARID1A being reported with the highest mutation rate $(n=6 / 51,11.7 \%)$ in ctDNA of HCC patients in a European cohort [59]. Other mutations identified in ctDNA of HCC patients comprise the oncogenes KRAS, NRAS and TERT, and the tumour suppressor $A X I N 1$, which are involved in several major tumour progression pathways (e.g. MAPK/RAS, telomere maintenance, p53 signalling and Wnt- $\beta$ catenin pathway) [60-62]. In addition to genetic alterations, altered DNA methylation patterns, notably characterized by global hypomethylation and region-specific hypermethylation, are early events during carcinogenesis [63]. Cai et al. performed a genome-wide mapping of 5-hydroxymethylcytosines $(5 \mathrm{hmC})$ using plasma cfDNA collected from a Chinese cohort $(n=1,204)$ and developed a 32-gene panel capable of distinguishing early HCC patients from high-risk individuals (e.g. chronic hepatitis and/or liver cirrhosis patients) based on $5 \mathrm{hmC}$ distribution. This novel panel significantly outperformed AFP measurement, being able to identify HCC patients with $<20 \mathrm{ng} / \mathrm{ml}$ AFP levels who otherwise would be wrongfully diagnosed [64].

Determining the methylation status of oncogenes and tumour suppressor genes in ctDNA is a method for understanding tumour biology and guiding therapeutical strategies. For instance, Ras association domain family 1 isoform A (RASSF1A) hypermethylation was detected in the serum of 93\% (59 out of 63) of HBV-related HCC patients in comparison to only 8\% (4 out of 50) of healthy individuals [65]. Considering AFP-negative tumours present a clinical challenge in the diagnosis of HCC, Lu et al. demonstrated that the hypermethylation of RASSF1A, COX2 and APC genes in plasma ctDNA can be used to identify HCC patients with $<20 \mathrm{ng} / \mathrm{ml} \mathrm{AFP}$, besides being negatively correlated to tumour recurrence and overall survival [66]. Altogether, these studies indicate that cell-free circulating DNA is useful not only to identify patients in early stages of the disease but also to be used as prognostic markers (see Table 1). 
Table 1 - Recent studies suggesting the application of ctDNA in the clinical management of HCC

\begin{tabular}{|c|c|c|c|c|c|}
\hline Sample & Cohorts & Method & ctDNA level/mutations findings & Clinical significance & Ref. \\
\hline Plasma & $\begin{array}{l}72 \mathrm{HCC} \\
37 \mathrm{CLD} \\
42 \mathrm{HC}\end{array}$ & $\mathrm{qPCR}$ & Higher cfDNA levels in HCC patients (173ng/mL) than HC $(9 \mathrm{ng} / \mathrm{mL})$ & $\begin{array}{l}\text { Diagnosis: plasma ctDNA + AFP levels to discriminate HCC vs HC } \\
\text { Prognosis: plasma ctDNA levels correlated with tumour size, MVI and/or metastasis }\end{array}$ & [52] \\
\hline Plasma + tumour tissue & $\begin{array}{l}231 \mathrm{Gl} \text { cancers } \\
(31 \mathrm{HCC})\end{array}$ & NGS & $58 \%$ of patients with $>1$ alteration: TP53 (36\%), KRAS (25\%), and PIK3CA (9\%) & $\begin{array}{l}\text { Diagnosis and prognosis: HCC ctDNA more frequently altered than other cancers, with } \\
\text { high concordance (91-96\%) between tissue and ctDNA samples }\end{array}$ & [67] \\
\hline Plasma & $35 \mathrm{HCC}$ & NGS & Mutations: TP53 (18\%), TERT (14\%), CTNNB1 (13\%), ARID1A (9\%), MYC (5\%) & Diagnosis: development of a 73-gene panel to distinguish $\mathrm{HCC}$ vs $\mathrm{HC}$ & [68] \\
\hline Plasma & $14 \mathrm{HCC}$ & NGS & $\begin{array}{l}\text { Point mutations: TP53 (57\%), CTNNB1 (29\%) } \\
\text { Amplification: CDK6 (14\%), EGFR (14\%), MYC (14\%) }\end{array}$ & $\begin{array}{l}\text { Targeted therapy: use of cabozantinib (MET inhibitor), palbociclib (CDK4/6 inhibitor), } \\
\text { and celecoxib (COX-2/Wnt inhibitor) based on ctDNA/tissue findings }\end{array}$ & [57] \\
\hline Plasma + tumour tissue & $\begin{array}{l}26 \mathrm{HCC} \\
10 \mathrm{LC} \\
10 \mathrm{CLD}\end{array}$ & $\begin{array}{l}\text { Fluorometry } \\
\text { NGS }\end{array}$ & $\begin{array}{l}\text { Mutations in } 96.2 \% \text { of samples: TP53 (50\%). AXIN1 (11.54\%), BCOR (11.54\%), } \\
\text { and CTNNB1 (11.54\%) }\end{array}$ & $\begin{array}{l}\text { Prognosis: number of mutations/ctDNA concentration correlated with tumour size; } \\
\text { detectable mutations in postoperative plasma correlated to poor DFS }\end{array}$ & [58] \\
\hline Plasma + tumour tissue & $\begin{array}{l}41 \mathrm{HCC} \\
10 \mathrm{HC}\end{array}$ & NGS & $\begin{array}{l}\text { HCC-associated mutations in } 8 \text { patients }(19.5 \%): \text { CTNNB1 }(9.8 \%), \text { TERT } \\
(4.9 \%), \text { TP53 (4.9\%) }\end{array}$ & Prognosis: recurrence within 1 year in all patients with ctDNA somatic mutations $\geq 1$ & [69] \\
\hline Serum & $\begin{array}{l}66 \mathrm{HCC} \\
43 \mathrm{CLD}\end{array}$ & $\begin{array}{l}\text { Methylation } \\
\text { MS-PCR }\end{array}$ & $\begin{array}{l}\text { INK4A promoter region methylation: } 6.6 \% \text { of the } 7 \mathrm{CpG} \text { methylated (vs } 2.2 \% \\
\text { in } \mathrm{HC} \text { ) }\end{array}$ & $\begin{array}{l}\text { Diagnosis: INK4A methylation to differentiate HCC and non-HCC patients (ROC 0.82, } \\
65.3 \% \text { sensitivity and } 87.2 \% \text { specificity) }\end{array}$ & [70] \\
\hline Plasma + tumour tissue & $\begin{array}{l}203 \mathrm{HCC} \\
104 \mathrm{CH} \\
50 \mathrm{HC}\end{array}$ & $\begin{array}{l}\text { Methylation } \\
\text { MS-PCR }\end{array}$ & $\begin{array}{l}\text { Significant hyper-methylation of APC, COX2 and RASSF } 1 A \text { in HCC samples vs } \\
\text { non-HCC }\end{array}$ & $\begin{array}{l}\text { Diagnosis: COX2 methylation to detect HBV-related HCC patients, and a combinatory } \\
\text { model (APC, COX2 and RASSF1A) to detect AFP-negative HCC patients }\end{array}$ & [66] \\
\hline Plasma + tumour tissue & $29 \mathrm{HCC}$ & NGS & $\begin{array}{l}\text { Mutation: TP53 (50\%), ATM (39\%), ALK (36\%), NPM1 }(36 \%) \text {, and CSF1R }(36 \%) \\
75 \% \text { consistency between plasma ctDNA and tissue samples }\end{array}$ & $\begin{array}{l}\text { Diagnosis and prognosis: ctDNA-positive patients present higher AFP levels } \\
\text { Prognosis: higher MAF in TP53, CTNNB1, PIK3CA, and CDKN2A genes correlated with } \\
\text { tumour size/number and metastasis }\end{array}$ & [71] \\
\hline Plasma + tumour tissue & $\begin{array}{l}51 \mathrm{HCC} \\
10 \mathrm{LC}\end{array}$ & NGS & Mutations: ARID1A (11.7\%), CTNNB1 (7.8\%) and TP53 (7.8\%) & Prognosis: ctDNA levels increase during disease progression & [59] \\
\hline Plasma + tumour tissue & $\begin{array}{l}33 \mathrm{HCC} \\
6 \mathrm{HC}\end{array}$ & NGS & $\begin{array}{l}\text { Mutations: TP53 (64\%), ARID1A (24\%), AXIN1 (21.2\%), PTEN (12.1\%) } \\
52-84 \% \text { of the tissue DNA mutations detected in ctDNA }\end{array}$ & $\begin{array}{l}\text { Diagnosis: ctDNA mutation panel to discriminate HCC vs. non-HCC } \\
\text { Prognosis: plasma ctDNA mutation rate correlated with tumour recurrence }\end{array}$ & [72] \\
\hline
\end{tabular}




\begin{tabular}{|c|c|c|c|c|c|}
\hline Plasma & $48 \mathrm{HCC}$ & Fluorimetry & $\begin{array}{l}\text { Higher cfDNA levels in high-HBV (vs. low-HBV), single (vs. multiple tumours), } \\
\text { and BCLC O/A (vs. BCLC C) }\end{array}$ & $\begin{array}{l}\text { Prognosis: increased cfDNA levels associated with poor liver function, underlying } \\
\text { cirrhosis, and tumour characteristics (tumour size, number and stage) }\end{array}$ & [73] \\
\hline $\begin{array}{l}\text { Serum, plasma, tumour } \\
\text { and peritumour tissue }\end{array}$ & $34 \mathrm{HCC}$ & NGS & Mutations: TERT (44.1\%), TP53 (26.4\%), CTNNB1 (17.6\%) and TTN (11.8\%) & $\begin{array}{l}\text { Diagnosis: ctDNA levels improve the detection of minimal residual disease } \\
\text { Prognosis: plasma ctDNA level correlates with poor DFS and OS rates }\end{array}$ & [60] \\
\hline Plasma & $\begin{array}{l}151 \mathrm{HCC} \\
14 \mathrm{HC}\end{array}$ & NGS & $\begin{array}{l}\text { Focal amplifications: 1q21.3 (MCL1), 7q31.2 (MET), 8q24.21 (MYC), 11q13.3 } \\
\text { (CCND1), and deletions at 17p13.1 (TP53) }\end{array}$ & $\begin{array}{l}\text { Prognosis: increased cfDNA level associated with shorter O.S. and TTP } \\
\text { Response to therapy: cfDNA concentration correlated with response to sorafenib }\end{array}$ & [54] \\
\hline Plasma & $\begin{array}{l}24 \mathrm{HCC} \\
86 \mathrm{CHB}\end{array}$ & Fluorimetry & Increased cfDNA concentration in $\mathrm{HCC}$ patients vs $\mathrm{HC}$ & Diagnosis: the HCC index (age, AFP, and cfDNA) to diagnose HCC vs HC & [74] \\
\hline Plasma + tumour tissue & $8 \mathrm{HCC}$ & ddPCR & $\begin{array}{l}\text { Mutations in } 6 \text { out of } 8 \text { patients }(75 \%): \text { TERT promoter }(5 / 8) \text {, TP53 (3/8), } \\
\text { CTNNB1 (2/8), JAK1 (1/8) or AXIN1 (1/8) }\end{array}$ & $\begin{array}{l}\text { Diagnosis: specific TP53 allele variants can detect patients with low AFP using plasma } \\
\text { ctDNA }\end{array}$ & [61] \\
\hline Plasma + tumour tissue & $\begin{array}{l}218 \mathrm{HCC} \\
81 \mathrm{LC}\end{array}$ & $\begin{array}{l}\text { Fluorimetry } \\
\text { ddPCR }\end{array}$ & $\begin{array}{l}\text { TERT promoter mutation in } 104 \text { out of } 218 \text { patients }(47.7 \%) \\
\text { ctDNA TERT promoter mutation related to HCV, cirrhosis, family history of } \\
\text { cancer and poor prognosis }\end{array}$ & $\begin{array}{l}\text { Surveillance and prognosis: TERT promoter mutation associated with HCV-status, } \\
\text { hepatic cirrhosis, family history of cancer, and poor prognosis }\end{array}$ & [75] \\
\hline Plasma & $206 \mathrm{HCC}$ & NGS & $\begin{array}{l}\text { Alteration in } 87.8 \%(181 / 206) \text { of patients: TP53, EGFR, MET, ARID1A, MYC, } \\
\text { NF1, BRAF, and ERBB2 }\end{array}$ & Diagnostic: plasma ctDNA mutation rates to detect HBV-related HCC patients & [62] \\
\hline Plasma & $\begin{array}{l}1204 \mathrm{HCC} \\
392 \mathrm{CHB} \\
570 \mathrm{HC}\end{array}$ & Methylation & Liver-derived H3K4me1 and H3K27ac marks increased in HCC patients & Diagnosis: $5 \mathrm{hmC}$ measurement to identify low-AFP (<20ng/ml) HCC patients & [64] \\
\hline Plasma & $55 \mathrm{HCC}$ & Fluorimetry & $\begin{array}{l}\text { Lower cfDNA concentration in patients who respond to } \mathrm{RT}(35.9 \mathrm{ng} / \mathrm{ml}) \text { vs. } \\
\text { nonresponders }(56.1 \mathrm{ng} / \mathrm{ml})\end{array}$ & $\begin{array}{l}\text { Prognosis: cfDNA level to predict RT outcome, O.S., hepatic failure rates and tumour } \\
\text { recurrence }\end{array}$ & [55] \\
\hline
\end{tabular}

CH - Chronic hepatitis, CHB - Chronic hepatitis B, CLD - Chronic Liver Disease, DFS - Disease-Free Survival, GI - Gastrointestinal, HC - Healthy control, HCC - Hepatocellular carcinoma, LC - Liver cirrhosis, MAF -

Multiple Allele Frequency, MVI - Microvascular invasion, OS - overall-survival, RT - Radiotherapy, TTP - time-to-progression 


\subsubsection{Circulating microRNA in hepatocellular carcinoma}

In 2018, Xia et al. analysed transcriptomic datasets from The Cancer Genome Atlas (TCGA), the Gene Expression Omnibus (GEO), and Oncomine from 920 HCC tissue samples. They identified 23 genes significantly altered in HCC patients, targeted by 9 differentially expressed miRNAs and 21 IncRNAs [76]. Xia et al. were unable to perform this analysis in serum due to the lack of publicly available data. In a separate study using RNA-seq, the upregulation of oncogenic miRNAs miR-21 and miR-10b was detected in paired tissue and serum samples from HCC patients ( $n=89)$, and miR-21 correlated with poorer prognosis [77]. Lin et al. developed a serum miRNA panel-miR-29a, miR-29c, miR-133a, miR143, miR-145, miR-192, and miR-505 - that outperforms AFP and correctly diagnosed AFP-negative HCC. Samples were prospectively collected from patients under surveillance for HCC, and the panel identified preclinical HCC 12 months before diagnosis [78].

Elemeery et al. analysed the serum of 200 HCC patients in comparison to 200 cirrhotic individuals. Two miRNAs, miR-34a, miR-221, were upregulated in HCC, whereas five others were downregulated, miR-16, miR-23-3p, miR-122-5p, miR-198, miR-199a3p [79]. MiR-122, an EMTregulator abundant in the liver, is down-regulated in HCC tissue and serum. Low miR-122 expression is associated with metastasis and the restoration of its expression sensitizes HCC cells to sorafenib, suggesting its use as a biomarker for prognosis and treatment $[80,81]$. Both miR-122 and anti-miR-21 were investigated as potential therapies for HCC using miR-loaded nanoparticles delivered directly into the tumour. The authors reported an immunomodulation of protumoral (IL-1 $\alpha$, IL-1 13, IL- 6 and IL-17) and antitumoral (IL-2 and IL-12) cytokines, enhancing the effect of doxorubicin [82].

An et al. reported the diagnostic value of serum miR-375, miR-10a, and miR-423, which are upregulated in the sera of HCC patients. All four circulating miRNA included in this study decreased after the removal of the tumour, highlighting their potential to be used as biomarkers to monitor recurrence after surgery [83]. Other plasma microRNAs usually overexpressed in HCC include miR-20a5p, miR-25-3p, miR-30a-5p, miR-92a-3p, miR-132-3p, miR-185-5p, miR-320a and miR-324-3p [84]; whereas miR-218 [85], miR-1246 and miR-3126-5p [86] are downregulated. The absence of studies validating miRNAs as biomarkers in a large cohort, and the high costs for isolating miRNAs, primers and amplification limit their application for screening and diagnostic purposes. In addition, it is interesting to note that the variability of miRNA targets across these various studies suggests the protein profiles may differ between serum and tissue; it indicates that the processing of blood, predominantly in the kidneys, may alter circulating miRNA profile. 


\subsection{Circulating Tumour Cells (CTCs) detection and characterization}

Circulating tumour cells (CTCS) are cells that are shed from a primary tumour or metastatic lesion and enter the circulatory system. CTCs can be isolated from peripheral blood and used to determine therapeutic targets and biomarkers because they mimic tumour properties [87]. Several limitations have halted the advances in the clinical use of CTCs. First, early stages of cancer present significantly lower levels of CTCs; thus, CTC count tends to be proportional to the tumour volume. In addition, only $0.01 \%$ of the cells that enter the circulation survive to produce metastasis. Finally, CTC populations are highly heterogeneous regarding phenotype and genotype which makes it challenging to establish standard detection methods $[44,88]$.

Recent technologies for isolating CTCs can be divided into two categories: physical and biological methods. The former relies on physical properties of the cell such as density, deformability, electric charge and size, and can be isolated using filtration or ficoll centrifugation, for instance [88]. In contrast, biological approaches rely on tumour-specific biomarkers which include cell receptors (HER2), epithelial markers (EpCAM), and site-specific antigens such as the prostate-specific antigen (PSA). Currently, the CellSearch ${ }^{\mathrm{TM}}$ system is the only FDA-approved method for isolating CTCS, which captures tumour cells using anti-EpCAM-coated magnetic beads [89]. This method presents a limitation because, although EpCAM is expressed in most epithelial-derived cells and not in blood cells, highly metastatic tumour cells undergoing epithelial-mesenchymal transition (EMT) are not isolated. Consequently, more recent devices using microfluidic chip systems and nanotechnologies in combination with surface biomarker detection have been proposed [87, 90].

\subsubsection{CTCs in hepatocellular carcinoma}

Schulze et al. detected CTCS in the peripheral blood of 18 out of 59 HCC patients (30.5\%). Following their isolation using the CellSearch ${ }^{\mathrm{TM}}$ System, CTCS were stained for cytokeratin (CK) as a cancer marker, as well as with CD45 to exclude haematopoietic cells. The authors reported an association between CTC detection and tumour BLCL stage, with stage C ( $n=11 / 19,57.8 \%)$ significantly higher than stages $A(n=1 / 9,11.1 \%)$ and $B(n=6 / 31,19.3 \%)$. CTC-positive patients had shorter overall survival (460 days) compared to those without CTCs (746 days) [91]. The characterization of EpCAMpositive CTCs was performed by Kelley et al., who first reported the isolation and the genomic characterization of CTCs using Whole-Genome Amplification followed by next-generation sequencing. A total of 58 somatic mutations were detected in CTC-derived DNA, including TP53 and PTEN variants characteristic of liver cancer, which were further confirmed in matching peripheral blood mononuclear 
cells (PBMC) and tumour tissue samples [92]. Genetic alterations were also reported by Xu et al., who isolated CTCS from 69 out of 81 HCC patients (85.1\%). Two patients presented HER-2 gene amplification with chromosome 17 gain, and six showed TP53 deletion evaluated using fluorescence in situ hybridization (FISH) [93].

HCC cells are highly heterogeneous with only a small percentage (0-35\%) presenting EpCAM expression, and a group of EPCAM-negative cells can be found even within tumours considered positive for this marker [94]. A multimarker combination has been proposed as a method to detect cells that accurately reflect tumour heterogeneity. Qi et al. isolated CTCs from 101/112 HCC patients using the CanPatrol ${ }^{\mathrm{TM}}$ System and further characterized tumour cells using RNA in situ hybridization targeting EpCAM, vimentin and Twist to capture cells undergoing EMT. Interestingly, CTCs were detected in two out of the twelve HBV patients in the control group of the study, who were followed every 1-2 months and developed small HCC nodules no longer than 5 months after sample collection [90]. In 2018, mesenchymal CTCs were detected in the blood of HCC patients using multiplex RNA in situ hybridization (RNA-ISH) targeting epithelial (CK8, CK18, CK19 and EpCAM) and mesenchymal (vimentin and Twist) markers. In a follow-up approximately 30 days after surgery, patients who had higher CTC counts presented increased tumour recurrence rates and shortened disease-free survival. The authors compare the prognostic value of EPCAM-positive and mixed (epithelial + mesenchymal) CTCs, showing that the later provides more accurate outcomes [95]. Other HCC-specific markers used in CTCs studies include glypican-3 (GP3), CD44, glutamine synthetase (GS), and HepPAr-1 (see Table 2) [44, 90]. 
Table 2 - Recent studies that detected circulating tumour cells (CTCS) in HCC patients

\begin{tabular}{|c|c|c|c|c|c|c|}
\hline HCC status & Cohorts & CTC isolation & CTC detection and analysis & CTC count & Concluding remarks & Ref \\
\hline $\begin{array}{l}\text { Treatment-naïve } \\
\text { non-metastatic }\end{array}$ & $\begin{array}{l}85 \mathrm{HCC} \\
20 \mathrm{CLD} \\
7 \text { other cancers }\end{array}$ & $\begin{array}{l}\text { Density gradient } \\
\text { centrifugation } \\
\text { FACS }\end{array}$ & $\begin{array}{l}\text { CK-7/8-positive, CD45- and CD235a- } \\
\text { negative }\end{array}$ & $38.8 \%(33 / 85)$ of patients presenting $\geq 5$ CTC (median=3). & $\geq 5$ CTCs correlated with higher MVI, lower DFS and OS & [96] \\
\hline $\begin{array}{l}\text { Pre- and post- } \\
\text { resection }\end{array}$ & $\begin{array}{l}105 \mathrm{HCC} \\
132 \mathrm{LC}\end{array}$ & $\begin{array}{l}\text { Taper slit filter } \\
\text { platform }\end{array}$ & $\begin{array}{l}\text { CK-positive, CD45-negative staining, } \\
\text { and morphological features }\end{array}$ & Increased CTC count after surgery in 25/105 patients & Post-operative CTC count predict tumour recurrence and OS & [97] \\
\hline $\begin{array}{l}\text { Pre- and post- } \\
\text { resection }\end{array}$ & $\begin{array}{l}112 \mathrm{HCC} \\
20 \mathrm{CHB} \\
12 \mathrm{HC}\end{array}$ & CanPatrol $^{\mathrm{TM}}$ & $\begin{array}{l}\text { CD45, EpCAM, CK8/19, vimentin and } \\
\text { Twist mRNA levels }\end{array}$ & $\begin{array}{l}\text { - } \geq 1 \text { CTCs in } 90.18 \% \text { (101/112) patients } \\
\text { - CTCs increased } 1-2 \text { months before detectable nodules } \\
\text { appeared in patients with recurrence }\end{array}$ & $\begin{array}{l}\text { - Combination of epithelial and mesenchymal markers improve } \\
\text { CTC detection in HCC } \\
\text { - Preoperative CTC count } \geq 16 \text { and mesenchymal-CTC } \\
\text { proportion } \geq 2 \% \text { can predict early recurrence }\end{array}$ & [90] \\
\hline $\begin{array}{l}\text { Treatment-naïve, } \\
\text { pre-and post- } \\
\text { resection }\end{array}$ & $\begin{array}{l}139 \mathrm{HCC} \\
23 \mathrm{BLT}\end{array}$ & CellSearch $^{\mathrm{TM}}$ & EpCAM- and CK-positive, CD45-negative & $\begin{array}{l}\text { Pre-operative: } 43.9 \% \text { of patients (median=1.13); post- } \\
\text { operative: } 54 \% \text { of patients (median=1.54) }\end{array}$ & $\begin{array}{l}\text { - Pre-operative CTC count predict outcomes after tumour } \\
\text { resection; post-operative CTC } \geq 2 \text { associated with shorter DFS }\end{array}$ & [98] \\
\hline $\begin{array}{l}\text { metastatic HCC } \\
\text { treated with } \\
\text { systemic } \\
\text { therapies }\end{array}$ & $\begin{array}{l}20 \mathrm{HCC} \\
10 \mathrm{LD}\end{array}$ & CellSearch $^{\mathrm{TM}}$ & EpCAM- and CK-positive, CD45-negative & $\begin{array}{l}8 / 20 \text { CTC-positive, with CTCs increased in AFP }>400 \mathrm{ng} / \mathrm{ml} \\
(7 / 10) \text { vs. AFP }<400 \mathrm{ng} / \mathrm{ml}(1 / 10) \text {; and with } \mathrm{MVI}(8 / 13) \mathrm{vs} \text {. } \\
\text { without MVI }(0 / 7)\end{array}$ & $\begin{array}{l}\text { - First report of efficient isolation and NGS of CTC in HCC } \\
\text { - Identification of characteristic mutations associated with HCC } \\
\text { (TP53 and PTEN) }\end{array}$ & [92] \\
\hline $\begin{array}{l}\text { Non-metastatic, } \\
\text { pre- and post- } \\
\text { resection }\end{array}$ & $73 \mathrm{HCC}$ & CellSearch $^{\mathrm{TM}}$ & $\begin{array}{l}\text { EpCAM- and pan-CK-positive, CD45- } \\
\text { negative }\end{array}$ & $\begin{array}{l}\text { - Variation in CTC count depends on site, higher in hepatic } \\
\text { veins }(80.82 \%) \text { than peripheral blood vessels }(45.21-68.49 \%)\end{array}$ & $\begin{array}{l}\text { - First study to demonstrate the spatial distribution of } \\
\text { epithelial and mesenchymal CTCs } \\
\text { - Preferential spread of cells from HV to the lungs and PV/PA } \\
\text { intra-hepatically }\end{array}$ & [99] \\
\hline $\begin{array}{l}\text { Variable tumour } \\
\text { stage and } \\
\text { treatment }\end{array}$ & $\begin{array}{l}59 \mathrm{HCC} \\
19 \mathrm{HC}\end{array}$ & CellSearch $^{\mathrm{TM}}$ & EpCAM- and CK-positive, CD45-negative & - CTCs detected in $18 / 59 \mathrm{HCC}$ patients (30.5\%) & $\begin{array}{l}\text { - CTC count associated with tumour BCLC stage and OS ( } 460 \\
\text { days in CTC-positive vs } 746 \text { days in CTC-negative) }\end{array}$ & [91] \\
\hline $\begin{array}{l}\text { Treatment-naïve } \\
\text { patients }\end{array}$ & $\begin{array}{l}54 \mathrm{HCC} \\
5 \mathrm{HC}\end{array}$ & Labyrinth ${ }^{\mathrm{TM}}$ & $\begin{array}{l}\text { CD44-, GPC3- and HepPar-1-positive, } \\
\text { CD45-negative }\end{array}$ & - $\geq 1$ CTC detected in 37 out of 42 patients (88.1\%) & $\begin{array}{l}\text { - CTC number associated with TNM stage and macrovascular } \\
\text { invasion } \\
\text { - CTC clusters detected more frequently in TNM stages II-IV } \\
(65.4 \%) \text { than } 0-1(43.8 \%)\end{array}$ & [94] \\
\hline
\end{tabular}

BCLC - Barcelona-Clinic Liver Cancer, BLT - Benign Liver Tumour, DFS - Disease-Free Survival, HV - Hepatic vein, MVI - Microvascular invasion, NGS - Next Generation Sequencing, OS - Overall-Survival, PA - Portal

artery, PV- Portal vein, RNA-ISH - RNA in situ hybridization, WGA - Whole Genome Amplification 


\subsection{Proteomics and circulating protein biomarkers for HCC}

Currently, the use of protein biomarkers in HCC diagnosis is limited to AFP, however, its suboptimal diagnostic performance led the American Association for the Study of Liver Diseases (AASLD) to no longer require AFP testing as part of the diagnostic evaluation [20,43]. Proteomics can identify and measure protein abundance in several fluids, therefore it could be used in the development of novel biomarkers. Recent efforts towards establishing HCC proteome databases were made possible by advances in high-throughput mass spectrometry-based tools including matrix-assisted laser desorption/ionization-time of flight MS (MALDI-TOF), or gel-based techniques such as 2-dimensional difference gel electrophoresis (2-DIGE). [100]. Currently, protein identification is achieved either by performing a proteolytic digestion of proteins into peptides prior to mass spectrometry analysis, also known as a "bottom-up approach"; or by using separation methods to analyse intact proteins in complex biological samples, which is known as "top-down approach" [101].

Yang et al performed a comparison between the secretome of the primary culture of paired HCC cells and non-tumorous adjacent liver tissue and identified 1,365 differentially abundant proteins. Among these, 4 proteins were validated using plasma samples of 179 HCC patients, in which circulating MMP-1 and osteopontin (OPN) showed a greater ability to differentiate HCC patients from those with decompensated cirrhosis than AFP measurements [102]. Using an untargeted MS approach, Tsai et al. compared sera protein composition of $97 \mathrm{HCC}$ and 118 liver cirrhosis patients following the depletion of high-abundant proteins. The authors identified 5 proteins associated with HCC significantly different between cohorts - apolipoprotein A-II (APOA2), clusterin (CLU), complement factor B (CFB), apolipoprotein C (APOC) and vitronectin (VTN) - in addition to 11 new biomarker candidates confirmed using targeted multiple-reaction monitoring-mass spectrometry (MRM-MS). Together with AFP, this 5protein panel was used to detect HCC with an AUC of 0.80 [103]. Other protein biomarkers discovered using proteomics include CD14 [104], clusterin (CLU), inter- $\alpha$-trypsin inhibitor heavy chain H4 (ITIH4), apolipoprotein B-100 (APOB-100) [105], FOS-like antigen 2 (FOSL2) and fibrinogen gamma chain (FGG) [106]. However, most of these consist of case-control studies aiming to develop clinical assays, thus lacking retrospective longitudinal results to evaluate their feasibility in a clinical setting.

Proteomics findings can also be used to monitor response to liver cancer therapy (see Table 3). Yu et al. collected blood samples from $180 \mathrm{HCC}$ patients before and after doxorubicin-based TACE and evaluated changes in protein composition using MRM-MS. Five proteins - leucine-rich alpha-2glycoprotein (LRG1), serum amyloid P-component (APCS), cholinesterase (BCHE), complement component 7 (C7), and ficolin-3 (FCN3) - were significantly different between patients with a complete response to TACE and those in which the treatment was ineffective [107]. Liu et al. identified 27 
differentially expressed proteins in serum samples of HCC patients $(n=16)$ and healthy individuals using isobaric tags for relative and absolute quantitation (iTRAQ)-based LC-MS/MS, most of which were associated to the nuclear factor-K beta (NFK-B) and ERK1/2 pathways. The follow-up of patients who underwent curative resection revealed that increased levels of phosphoglycerate kinase 1 (PGK1) three, six or nine months after surgery are positively correlated to tumour recurrence. Thus, PGK1 could be used as a prognostic marker in combination with AFP [108]. Shen et al. reported an increase in the serum levels of ficolin-3 in patients $(n=52)$ who respond to radiofrequency ablation therapy, with 3year disease-free survival rates of $50.0 \%$ compared to only $22.7 \%$ in the low ficolin-3 group [109]. These results are interesting considering the immune-related properties of ficolin-3 and the crescent interest in combining locoregional therapies and immunotherapy [110]. Altogether, these findings suggest that targeted proteomics-based models can be used to predict clinical outcomes and to help determine suitable therapeutic strategies for HCC.

In addition to AFP, the use of other serum proteins for disaese surveillance, diagnosis and prognosis of HCC has been proposed. Choi and co-authors evaluated the surveillance potential of serum AFP, lectin-reactive AFP (AFP-L3), and des- $\gamma$-carboxy prothrombin (DCP) in 689 patients with liver cirrhosis and/or viral hepatitis B[111]. In the 42 patients who developed HCC, serum AFP and AFP-L3 levels were significantly increased up to 6 months before the diagnosis, while DCP was unaltered. At diagnosis, the diagnostic performance of AFP (AUROC=0.77), AFP-L3 (AUROC=0.73) and DCP ( $A \cup R O C=0.71$ ) were inferior to the combination of AFP and AFP-L3 (AUROC $=0.83$, sensitivity $=79 \%$, and specificity=87\%) [111]. Other combinations reported for the diagnosis of HCC are dickkopf-1 (DKK-1), DCP and AFP (sensitivity=93\%, specificity=78\%)[112]; and AFP and DKK-1 alone (sensitivity=78.4\%, specificity=72.5\%)[113]. Those studies demonstrate that combining biomarkers is an interesting strategy to overcome the suboptimal performances of the circulating proteins currently used for the early detection of HCC.

Besides blood, other body fluids have been investigated using comprehensive proteomic analysis. Zhang and co-authors evaluated paired liver tumour tissue and hepatic interstitial fluid from 44 liver cancer patients, 17 individuals with other liver diseases and 30 healthy volunteers using iTRAQMS [100]. They identified two significantly increased proteins - secreted protein acidic and cysteinerich (SPARC) and thrombospondin-2 (THBS2) - in the interstitial fluid of HCC patients, both associated with the ECM in the tumour microenvironment. The diagnostic power of these biomarkers was investigated in the sera of $17 \mathrm{HCC}$ patients, in which they were able to discriminate HCC patients from healthy controls both alone (SPARC: $A U R O C=0.88$, sensitivity $=80 \%$, specificity $=93 \%$; THBS2 AUROC $=0.91$, sensitivity $=80 \%$, specificity $=93 \%$ ) and combined (AUROC $=0.97$, sensitivity $=86 \%$, specificity=100\%) [100]. 
Ding et al. compared the salivary protein composition of $15 \mathrm{HCC}$ patients and 15 healthy controls using iTRAQ-MS. Out of the 113 differentially abundant proteins identified between the cohorts, only superoxide dismutase 2 (SOD2) was confirmed by ELISA with an AUROC value of 0.9082 for detecting HCC [114]. As highlighted by the authors, the lack of liver tissue samples to validate those findings is a limitation to proteomics studies regarding circulating biomarkers. In 1993, You and coauthors developed an ELISA assay to detect salivary AFP levels. They reported a strong correlation $(r=0.978)$ between salivary and serum levels of AFP and increased salivary AFP in HCC patients compared to healthy subjects (1,367.8 ng/L vs $14.3 \mathrm{ng} / \mathrm{L}$, respectively) [115]. These findings, however, were not translated into the clinical management of HCC. 
Table 3 - Recent studies that identified serum protein biomarkers for HCC using proteomics

\begin{tabular}{|c|c|c|c|c|c|}
\hline Cohorts & Collection timepoints & Proteomic method & Target protein & Clinical relevance & Ref. \\
\hline $\begin{array}{l}19 \mathrm{HCC} \\
19 \mathrm{HC}\end{array}$ & At diagnosis & LC-MS/MS & $\begin{array}{l}\text { - Down-regulated: A1AT, SUMO, ITIH4, CFHR-4, CFH-1, CLU } \\
\text { - Up-regulated: Apo B-100 }\end{array}$ & Changes in protein glycosylation as a biomarker for HCC & [105] \\
\hline $57 \mathrm{HCC}$ & Pre- and post-RFA & $\begin{array}{l}\text { 2-DE } \\
\text { MALDI-TOF-MS/MS }\end{array}$ & $\begin{array}{l}\text { CLU, FCN3 and RBP4 } \\
\text { FCN3 increased in patients who respond to RFA }\end{array}$ & $\begin{array}{l}\text { - Patients with high-Ficolin-3 present longer disease-free survival (DFS) } \\
\text { - Immune-potentiating effect of RFA by increased ficolin-3. }\end{array}$ & [109] \\
\hline $\begin{array}{l}44 \mathrm{HCC} \\
17 \mathrm{CLD} \\
30 \mathrm{HC}\end{array}$ & At diagnosis & iTRAQ & SPARC and THBS2 & $\begin{array}{l}\text { High serum THBS2 level predicts } \mathrm{HCC} \text { recurrence and it is associated with } \\
\text { poor prognosis }\end{array}$ & {$[100]$} \\
\hline $\begin{array}{l}40 \mathrm{HCC} \\
40 \mathrm{HC}\end{array}$ & At diagnosis & 2D-LC-MS/MS & FGG, FOSL2 and MGAT5B increased in HCC & Use of circulating FGG, MGAT5B and FOSL2 to diagnose HCC & [106] \\
\hline $16 \mathrm{HCC}$ & Pre- and post-resection & $\begin{array}{l}\text { ITRAQ } \\
\text { 2D-LC-MS/MS }\end{array}$ & GO analysis: ERK1/2 and NF-kB signalling pathways enriched & $\begin{array}{l}\text { - Lipid homeostasis pathway is altered in HCC early-recurrence HC patients } \\
\text { - Post-operative serum PGK1 level predicts recurrence after } 3 \text { months }\end{array}$ & [108] \\
\hline $\begin{array}{l}50 \mathrm{HCC} \\
50 \mathrm{HC}\end{array}$ & At diagnosis & $\begin{array}{l}\text { 2-DE } \\
\text { MALDI-TOF/TOF }\end{array}$ & HS3ST3A1, $\beta$-tubulin, APOA-I, RAS, RLPLO, OSBPL11 and CCNH & $\begin{array}{l}\text { - Higher APOE and OSBPL11 levels associated with increased OS } \\
\text { - APOE increase correlated with tumour grade }\end{array}$ & [116] \\
\hline $\begin{array}{l}\text { HCC in } \\
\text { Wistar rats }\end{array}$ & Not provided & MALDI-TOF/TOF & CLU, NDRG2 and HSPa8 & $\begin{array}{l}\text { Validation of the dynamic changes in tumour and serum CLU, NDRG2 and } \\
\text { HSPa8 during carcinogenesis in HCC-bearing rats }\end{array}$ & [117] \\
\hline $\begin{array}{l}97 \mathrm{HCC} \\
118 \mathrm{LC}\end{array}$ & At diagnosis & LC-MS/MS & APOA2, CLU, CFB, APCS, and VTN & $\begin{array}{l}\text { Development of a 6-protein panel to detect HCC which outperformed AFP } \\
\text { measurement alone }\end{array}$ & [103] \\
\hline $\begin{array}{l}20 \mathrm{HCC} \\
20 \mathrm{HC}\end{array}$ & At diagnosis & $\begin{array}{l}\text { 2-DE } \\
\text { MALDI-TOF }\end{array}$ & HSP9O & Elevated serum HSP9O level to diagnose HCC & [118] \\
\hline $\begin{array}{l}184 \mathrm{HCC} \\
126 \mathrm{HBV}\end{array}$ & After resection & Human L-507 Array & MCP-1 and Prolactin & $\begin{array}{l}\text { Combination AFP+MCP-1 to diagnose HCC rendered an AUC of } 0.974 \text {, } \\
\text { higher than AFP alone (0.942) }\end{array}$ & [119] \\
\hline $51 \mathrm{HCC}$ & Pre- and post-RT & $\begin{array}{l}\text { 2-DE } \\
\text { MALDI-TOF }\end{array}$ & ITIH4, FGG, KRT9 and CA1 & Pre-RT serum ITIH4 level predicts response to treatment & [120] \\
\hline $\begin{array}{l}29 \mathrm{HCC} \\
38 \mathrm{CLD} \\
10 \mathrm{HC}\end{array}$ & Not provided & $\begin{array}{l}\text { iTRAQ } \\
\text { LC-MS/MS }\end{array}$ & GELS, QSOX1 and CD14 & $\begin{array}{l}\text { Serum CD14 level to discriminate HCC patients from advanced LC with } \\
\text { superior performance over AFP }\end{array}$ & [104] \\
\hline $180 \mathrm{HCC}$ & Pre- and post-TACE & SRM-MS & LRG1, APCS, BCHE, C7 and FCN3 & $\begin{array}{l}\text { A 5-protein panel in combination to AFP and PIVKA-II levels to predict } \\
\text { tumour recurrence after TACE }\end{array}$ & [107] \\
\hline
\end{tabular}

CLD - Chronic Liver Disease, HBV - Hepatitis B virus, HC - Healthy control, HCC - Hepatocellular carcinoma, RFA - Radiofrequency Ablation, RT - Radiotherapy, LC - Liver cirrhosis, TACE - Transarterial chemoembolization, 


\subsection{Metabolomics and HCC}

The profiling of metabolites in biofluids, known as metabolomics, provides information on systemic alterations that are related to the onset or the progression of liver cancer[121]. In recent years, metabolomic analysis were performed using nuclear magnetic resonance (NMR), and a combination of gas chromatography (GC), liquid chromatography (LC), and mass spectrometry (MS)based techniques. Kim and co-authors assessed the serum metabolite composition of $53 \mathrm{HCC}$ and 47 cirrhosis patients[122]. They developed a panel consisting of 5 metabolites - methionine, proline, ornithine, pimelylcarnitine, and octanoylcarnitine - that reliably distinguished HCC patients from those with cirrhosis ( $A \cup R O C=0.94$ ), outperforming the measurement of AFP ( $A \cup R O C=0.78$ ). They also identified the urea cycle, ammonia metabolism, and amino acid recycling as important pathways in the progression from cirrhosis to liver cancer [122]. In another study comparing plasma metabolites from HCC ( $n=63)$ and cirrhosis ( $n=65)$ patients, 11 metabolites were significantly altered between the cohorts [123]. The combination of these metabolites and clinical covariates, including AFP levels and Child-Pug h score, lead to a better diagnostic performance than AFP alone [123].

Considering liver cancer is related to a number of liver conditions, several authors have used metabolomics to understand eatiology-specific mechanisms of carcinogenesis. Gao and co-authors compared the serum metabolite composition of 49 HBV, 52 liver cirrhosis (LC) and 39 HCC patients, and identified a metabolic perturbation associated with energy metabolism, amino acid synthesis and redox balance across the groups[124]. They conclude that metabolites can be used as disease-specific biomarkers, namely phenylalanine, malic acid and 5-methoxytryptamine (HBV vs. healthy individuals), palmitic acid (LC vs. HBV), and asparagine and $\beta$-glutamate (HCC vs. LC)[124]. A variety of other tissue, serum, plasma and urine metabolites have been reported, however, their clinical utility remains under debate and further validation studies are necessary [125].

\subsection{Extracellular vesicles}

Extracellular vesicles (EVs) are membranous vesicles that are released by cells under physiological or pathological conditions. They may carry cargo such as membrane or cytosolic proteins, lipids, and various types of genetic material (DNA, mRNAs, miRNAs and other ncRNAs). Previously classified as cellular debris, EVs are currently considered mediators of intercellular communication. Therefore, protein- or RNA-loaded EVs are incorporated into the target cell via fusion with the cell membrane, potentially causing changes in phenotype [126]. EVs are classified according to their origin and size: exosomes are vesicles typically ranging from 30 to $150 \mathrm{~nm}$ in diameter mainly derived from endosomal 
membranes, and released via exocytosis; whereas microvesicles (MVs) are larger particles (50 to 1300 $\mathrm{nm}$ ) formed by the direct budding from the plasma membrane [126]. In liquid biopsies, circulating tumour-derived exosomes are isolated using sucrose-gradient separation and ultracentrifugation, the size and number of exosomes are assessed using transmission electron microscopy (TEM) and nanoparticle tracking analysis (NTA) and further confirmed using specific markers (e.g. CD9, CD37, CD63, ICAM-1 and integrins) which can be detected by western blot or flow cytometry [127]. In contrast to MVs, the role of exosomes in liver cancer has been extensively investigated (see Table 4). The majority of targets found were miRNAs and IncRNAs further emphasizing the importance of circulating RNAs as diagnostic markers. As for recent studies, HSP90B1, VCP and ALIX were the only proteins reported with differential abundance in HBV-positive HCC patients [128].

\subsubsection{Circulating tumour-derived exosomes in HCC}

In the last decade, several circulating HCC-derived exosomes containing miRNAs, mRNAs, IncRNAs and proteins have been identified. Recent studies regarding the use of exosomal biomarkers in HCC are summarized in Table 4. Mjelle et al. isolated exosomes from $145 \mathrm{HCC}$ patients using size-exclusion chromatography and performed a comprehensive transcriptomic analysis using RNA-seq. They reported a global increase of miRNA expression in HCC patients, as well as 40 miRNAs significantly different in this cohort compared to healthy individuals. The liver-specific miR-21 was 4-fold upregulated and correlated with a poor prognosis. The authors also determined specific miRNA and mRNA signatures associated with clinical features such as HBV-infection status and hepatic cirrhosis, indicating that exosomal RNA can be used as prognostic markers for HCC as well as to guide treatment protocols based on tumour molecular background [77]. Similarly, Min Shi et al. demonstrated that miR638 can be used both for the diagnosis and prognosis of HCC. They collected serum samples from 126 HCC patients and 21 healthy subjects and found that not only exosomal miR-638 expression was significantly lower in HCC patients in comparison to control subjects but also that patients with low miR-638 presented expressively higher tumour size, tumour-node-metastasis (TNM) stage and had reduced 5-year overall-survival rates [129]. Other dysregulated miRNAs have been reported in serum exosomes of HCC patients, such as miR-18a, miR-221, miR-222, miR-224, miR-101, miR-106b, miR-122, miR-195, which can distinguish HCC from viral hepatitis and hepatic cirrhosis [130].

A successful application of an exosomal RNA-based panel to detect HCC was performed by Gwad and co-authors, who evaluated changes in exosomal IncRNA-RP11-51315.6, miR-1262, and RAB11A mRNA expression between patients with HCC, chronic hepatitis $C$ and healthy individuals using qRT-PCR. The panel showed good diagnostic performance (96.7\% sensitivity and $95 \%$ specificity) to discriminate 
individuals with HCC. These RNA biomarkers were shown to independently predict tumour recurrence during a 44 month follow-up period [131]. Despite recent technical advances, there are no standard protocols to isolate and characterize the cargo of extracellular vesicles available, which halts their clinical application. 
Table 4 - Serum exosomal biomarkers studies in HCC

\begin{tabular}{|c|c|c|c|c|c|c|c|}
\hline Cohort & Exosome isolation & Exosome characterization & Exosome content & Quantification method & Molecule & Clinical significance & Ref \\
\hline $\begin{array}{l}76 \mathrm{HCC} \\
20 \mathrm{HC}\end{array}$ & Total Exosome Isolation kit ${ }^{\mathrm{TM}}$ & $\begin{array}{l}\text { TEM } \\
\text { WB: CD63 }\end{array}$ & IncRNA & qRT-PCR & LINC00161个 & Diagnosis: $\mathrm{HCC}$ vs HC & [132] \\
\hline $\begin{array}{l}10 \mathrm{HCC} \\
22 \mathrm{LC} \\
35 \mathrm{HCV}\end{array}$ & Ultracentrifugation & TEM & IncRNA & RT-PCR & InCRNA-HEIH $\downarrow$ & Diagnosis: HCV-related HCC vs $\mathrm{CHC}$ & [133] \\
\hline $\begin{array}{l}30 \mathrm{HCC} \\
30 \mathrm{HC}\end{array}$ & Total Exosome Isolation kit ${ }^{\mathrm{TM}}$ & WB: CD63 & IncRNA & RNA-seq & Lnc85个 & Diagnosis: AFP-negative HCC vs HC & [134] \\
\hline $145 \mathrm{HCC}$ & Size-exclusion chromatography & WB: CD63 & miRNA & RNA-seq & $\operatorname{miR}-21 \uparrow$ & Diagnosis: $\mathrm{HCC}$ vs $\mathrm{LC}$ and $\mathrm{HC}$ & [77] \\
\hline $59 \mathrm{HCC}$ & Ultracentrifugation & $\begin{array}{l}\text { TEM } \\
\text { WB: TSG101 }\end{array}$ & miRNA & RT-PCR & miR-718 $\downarrow$ & Prognosis: tumour recurrence after transplantation & [135] \\
\hline $\begin{array}{l}30 \mathrm{HCC} \\
30 \mathrm{LC} \\
30 \mathrm{CHB}\end{array}$ & ExoQuick Exosome Precipitation Solution ${ }^{\mathrm{TM}}$ & $\begin{array}{l}\text { TEM } \\
\text { NTA } \\
\text { WB: CD9 and CD63 }\end{array}$ & miRNA & qRT-PCR & miR-125b $\downarrow$ & $\begin{array}{l}\text { Diagnosis: } \mathrm{HCC} \text { vs } \mathrm{LC} \text { and } \mathrm{CHB} \\
\text { Prognosis: tumour recurrence }\end{array}$ & [136] \\
\hline $\begin{array}{l}88 \mathrm{HCC} \\
67 \mathrm{LC} \\
68 \mathrm{CHB} \\
68 \mathrm{HC}\end{array}$ & Ultracentrifugation & - & mRNA & RT-PCR & hnRNPH1 1 & $\begin{array}{l}\text { Diagnosis: } \mathrm{HCC} \text { vs } \mathrm{CHB} \\
\text { Prognosis: lymph node metastasis }\end{array}$ & [137] \\
\hline $\begin{array}{l}6 \mathrm{HCC} \\
4 \mathrm{HC}\end{array}$ & Differential centrifugation & WB: TSG101 & Protein & LC-MS/MS & $\begin{array}{l}\text { HSP9OB1 } \uparrow \\
\text { VCP } \uparrow \\
\text { ALIX } \downarrow\end{array}$ & Diagnosis: HBV-infected HCC patients & [128] \\
\hline
\end{tabular}

$\uparrow$ - upregulated, $\downarrow$ - downregulated, CHB - Chronic hepatitis B, CHC - Chronic hepatitis C, HC - Healthy control, HCC - Hepatocellular carcinoma, LC - Liver cirrhosis, NTA - Nanoparticle tracking analysis, TEM Transmission Electron Microscopy, WB - western blot 


\section{CONCLUSION}

The blood-based analysis of solid tumours has rapidly developed in recent years; however, the application of these findings still falls behind for HCC in comparison to other cancers. Liquid biopsies could improve HCC management in two main ways. First, biomarkers such as ctDNA, circulating RNAs and CTCs can provide knowledge regarding the genetic landscape of liver tumours, evidencing driver mutations and potential druggable targets [67]. Second, it can improve surveillance by allowing serial sampling from the same patient. The dynamic evaluation of these biomarkers provides valuable information regarding tumour progression, response to therapy, drug resistance and cancer recurrence [44]. As liquid biopsy remains an innovative field, further research is necessary to validate the potential of minimally invasive biomarkers in the diagnosis and prognosis of hepatocellular carcinoma. Further research is required to compare liquid biopsies to the tissue microenvironment in the liver. In addition, the efficacy of a liquid biopsy to aid in and improve on current HCC diagnosis and management strategies require further validation.

\section{Acknowledgments}

CP is funded by the Cancer Australia grant (APP1145657) and the Garnett Passe and Rodney Williams Foundation. LTFL is funded by the Gallipoli Medical Research Foundation PhD Scholarship. 


\section{References}

[1] J.D. Yang, P. Hainaut, G.J. Gores, A. Amadou, A. Plymoth, L.R. Roberts, A global view of hepatocellular carcinoma: trends, risk, prevention and management, Nat Rev Gastroenterol Hepatol 16(10) (2019) 589-604.

[2] F. Bray, J. Ferlay, I. Soerjomataram, R.L. Siegel, L.A. Torre, Ahmedin Jemal, Global Cancer Statistics 2018: GLOBOCAN Estimates of Incidence and Mortality Worldwide for 36 Cancers in 185 Countries, CA Cancer Journal for Clinicians 68 (2018) 394-424.

[3] A. Tang, O. Hallouch, V. Chernyak, A. Kamaya, C.B. Sirlin, Epidemiology of hepatocellular carcinoma: target population for surveillance and diagnosis, Abdom Radiol (NY) 43(1) (2018) 13-25.

[4] A. Forner, M. Reig, J. Bruix, Hepatocellular carcinoma, Lancet 391(10127) (2018) 1301-1314.

[5] M. Noureddin, M.E. Rinella, Nonalcoholic Fatty liver disease, diabetes, obesity, and hepatocellular carcinoma, Clin Liver Dis 19(2) (2015) 361-79.

[6] N. Kawada, K. Imanaka, T. Kawaguchi, C. Tamai, R. Ishihara, T. Matsunaga, K. Gotoh, T. Yamada, Y. Tomita, Hepatocellular carcinoma arising from non-cirrhotic nonalcoholic steatohepatitis, J Gastroenterol 44(12) (2009) 1190-4.

[7] K.L. Morris, J.D. Tugwood, L. Khoja, M. Lancashire, R. Sloane, D. Burt, P. Shenjere, C. Zhou, C. Hodgson, T. Ohtomo, A. Katoh, T. Ishiguro, J.W. Valle, C. Dive, Circulating biomarkers in hepatocellular carcinoma, Cancer Chemother Pharmacol 74(2) (2014) 323-32.

[8] Y. Hoshida, S.M. Nijman, M. Kobayashi, J.A. Chan, J.P. Brunet, D.Y. Chiang, A. Villanueva, P. Newell, K. Ikeda, M. Hashimoto, G. Watanabe, S. Gabriel, S.L. Friedman, H. Kumada, J.M. Llovet, T.R. Golub, Integrative transcriptome analysis reveals common molecular subclasses of human hepatocellular carcinoma, Cancer Res 69(18) (2009) 7385-92.

[9] J. Zucman-Rossi, A. Villanueva, J.C. Nault, J.M. Llovet, Genetic Landscape and Biomarkers of Hepatocellular Carcinoma, Gastroenterology 149(5) (2015) 1226-1239.e4.

[10] J. Calderaro, G. Couchy, S. Imbeaud, G. Amaddeo, E. Letouze, J.F. Blanc, C. Laurent, Y. Hajji, D. Azoulay, P. Bioulac-Sage, J.C. Nault, J. Zucman-Rossi, Histological subtypes of hepatocellular carcinoma are related to gene mutations and molecular tumour classification, J Hepatol 67(4) (2017) 727-738.

[11] N. Goossens, X. Sun, Y. Hoshida, Molecular classification of hepatocellular carcinoma: potential therapeutic implications, Hepat Oncol 2(4) (2015) 371-379.

[12] J.G. Chen, D.M. Parkin, Q.G. Chen, J.H. Lu, Q.J. Shen, B.C. Zhang, Y.R. Zhu, Screening for liver cancer: results of a randomised controlled trial in Qidong, China, J Med Screen 10(4) (2003) 204-9.

[13] J. Zhang, G. Chen, P. Zhang, X. Li, D. Gan, X. Cao, M. Han, H. Du, Y. Ye, The threshold of alphafetoprotein (AFP) for the diagnosis of hepatocellular carcinoma: A systematic review and metaanalysis, PLoS One 15(2) (2020) e0228857.

[14] P. Luo, S. Wu, Y. Yu, X. Ming, S. Li, X. Zuo, J. Tu, Current Status and Perspective Biomarkers in AFP Negative HCC: Towards Screening for and Diagnosing Hepatocellular Carcinoma at an Earlier Stage, Pathol Oncol Res (2019).

[15] N. Tsuchiya, Y. Sawada, I. Endo, K. Saito, Y. Uemura, T. Nakatsura, Biomarkers for the early diagnosis of hepatocellular carcinoma, World J Gastroenterol 21(37) (2015) 10573-83.

[16] J.M. Llovet, J. Zucman-Rossi, E. Pikarsky, B. Sangro, M. Schwartz, M. Sherman, G. Gores, Hepatocellular carcinoma, Nat Rev Dis Primers 2 (2016) 16018.

[17] F. Obuz, M. Oksuzler, M. Secil, O. Sagol, S. Karademir, H. Astarcioglu, Efficiency of MR imaging in the detection of malignant liver lesions, Diagn Interv Radiol 12(1) (2006) 17-21.

[18] E.B. Tapper, A.S. Lok, Use of Liver Imaging and Biopsy in Clinical Practice, N Engl J Med 377(8) (2017) 756-768.

[19] M.A. Silva, B. Hegab, C. Hyde, B. Guo, J.A.C. Buckles, D.F. Mirza, Needle track seeding following biopsy of liver lesions in the diagnosis of hepatocellular cancer: a systematic review and metaanalysis., Gut 57 (2008) 1592-1596.

[20] A. Vogel, A. Cervantes, I. Chau, B. Daniele, J.M. Llovet, T. Meyer, J.C. Nault, U. Neumann, J. Ricke, B. Sangro, P. Schirmacher, C. Verslype, C.J. Zech, D. Arnold, E. Martinelli, Hepatocellular carcinoma: 
ESMO Clinical Practice Guidelines for diagnosis, treatment and follow-up, Ann Oncol 29(Suppl 4) (2018) iv238-iv255.

[21] S. Tremosini, A. Forner, L. Boix, R. Vilana, L. Bianchi, M. Reig, J. Rimola, C. Rodriguez-Lope, C. Ayuso, M. Sole, J. Bruix, Prospective validation of an immunohistochemical panel (glypican 3, heat shock protein 70 and glutamine synthetase) in liver biopsies for diagnosis of very early hepatocellular carcinoma, Gut 61(10) (2012) 1481-7.

[22] L. Di Tommaso, G. Franchi, Y.N. Park, B. Fiamengo, A. Destro, E. Morenghi, M. Montorsi, G. Torzilli, M. Tommasini, L. Terracciano, L. Tornillo, R. Vecchione, M. Roncalli, Diagnostic value of HSP70, glypican 3, and glutamine synthetase in hepatocellular nodules in cirrhosis, Hepatology 45(3) (2007) 725-34.

[23] K. Schütte, C. Schulz, A. Link, P. Malfertheiner, Current biomarkers for hepatocellular carcinoma: Surveillance, diagnosis and prediction of prognosis, World J Hepatol 7(2) (2015) 139-49.

[24] R. Shrestha, K.R. Bridle, D.H.G. Crawford, A. Jayachandran, Immune checkpoint blockade therapies for HCC: current status and future implications, Hepatoma Research 5(32) (2019).

[25] J.M. Llovet, M.I. Real, X. Montana, R. Planas, S. Coll, J. Aponte, C. Ayuso, M. Sala, J. Muchart, R. Sola, J. Rodes, J. Bruix, Arterial embolisation or chemoembolisation versus symptomatic treatment in patients with unresectable hepatocellular carcinoma: a randomised controlled trial, Lancet 359(9319) (2002) 1734-9.

[26] T. Meyer, A. Kirkwood, M. Roughton, S. Beare, E. Tsochatzis, D. Yu, N. Davies, E. Williams, S.P. Pereira, D. Hochhauser, A. Mayer, R. Gillmore, J. O'Beirne, D. Patch, A.K. Burroughs, A randomised phase II/III trial of 3-weekly cisplatin-based sequential transarterial chemoembolisation vs embolisation alone for hepatocellular carcinoma, Br J Cancer 108(6) (2013) 1252-9.

[27] J.J. Harding, D.N. Khalil, G.K. Abou-Alfa, Biomarkers: What Role Do They Play (If Any) for Diagnosis, Prognosis and Tumor Response Prediction for Hepatocellular Carcinoma?, Dig Dis Sci 64(4) (2019) 918927.

[28] I.A. Ziogas, G. Tsoulfas, Evolving role of Sorafenib in the management of hepatocellular carcinoma, World J Clin Oncol 8(3) (2017) 203-13.

[29] M. Kudo, R.S. Finn, S. Qin, K.-H. Han, K. Ikeda, F. Piscaglia, A. Barion, J.-W. Park, G. Han, J. Jassem, J.F. Blanc, A. Vogel, D. Komov, T.R.J. Evans, C. Lopez, C. Dutcus, M. Guo, K. Saito, S. Kraljevic, T. Tamai, M. Ren, A.-L. Cheng, Lenvatinib versus sorafenib in first-line treatment of patients with unresectable hepatocellular carcinoma: a randomised phase 3 non-inferiority trial, The Lancet 391 (2018) 11631173.

[30] A.X. Zhu, R.S. Finn, J. Edeline, S. Cattan, S. Ogasawara, D. Palmer, C. Verslype, V. Zagonel, L. Fartoux, A. Vogel, D. Sarker, G. Verset, S.L. Chan, J. Knox, B. Daniele, A.L. Webber, S.W. Ebbinghaus, J. Ma, A.B. Siegel, A.L. Cheng, M. Kudo, Pembrolizumab in patients with advanced hepatocellular carcinoma previously treated with sorafenib (KEYNOTE-224): a non-randomised, open-label phase 2 trial, Lancet Oncol 19(7) (2018) 940-952.

[31] A.B. El-Khoueiry, B. Sangro, T. Yau, T.S. Crocenzi, M. Kudo, C. Hsu, T.Y. Kim, S.P. Choo, J. Trojan, T.H.R. Welling, T. Meyer, Y.K. Kang, W. Yeo, A. Chopra, J. Anderson, C. Dela Cruz, L. Lang, J. Neely, H. Tang, H.B. Dastani, I. Melero, Nivolumab in patients with advanced hepatocellular carcinoma (CheckMate 040): an open-label, non-comparative, phase 1/2 dose escalation and expansion trial, Lancet 389(10088) (2017) 2492-2502.

[32] A.X. Zhu, J.O. Park, B.Y. Ryoo, C.J. Yen, R. Poon, D. Pastorelli, J.F. Blanc, H.C. Chung, A.D. Baron, T.E. Pfiffer, T. Okusaka, K. Kubackova, J. Trojan, J. Sastre, I. Chau, S.C. Chang, P.B. Abada, L. Yang, J.D. Schwartz, M. Kudo, Ramucirumab versus placebo as second-line treatment in patients with advanced hepatocellular carcinoma following first-line therapy with sorafenib (REACH): a randomised, doubleblind, multicentre, phase 3 trial, Lancet Oncol 16(7) (2015) 859-70.

[33] A.X. Zhu, Y.K. Kang, C.J. Yen, R.S. Finn, P.R. Galle, J.M. Llovet, E. Assenat, G. Brandi, M. Pracht, H.Y. Lim, K.M. Rau, K. Motomura, I. Ohno, P. Merle, B. Daniele, D.B. Shin, G. Gerken, C. Borg, J.B. Hiriart, T. Okusaka, M. Morimoto, Y. Hsu, P.B. Abada, M. Kudo, Ramucirumab after sorafenib in patients with 
advanced hepatocellular carcinoma and increased alpha-fetoprotein concentrations (REACH-2): a randomised, double-blind, placebo-controlled, phase 3 trial, Lancet Oncol 20(2) (2019) 282-296.

[34] R.S. Herbst, J.-C. Soria, M. Kowanetz, G.D. Fine, O. Hamid, M.S. Gordon, J.A. Sosman, D.F. McDermott, J.D. Powderly, S.N. Gettinger, H.E.K. Kohrt, L. Horn, D.P. Lawrence, S. Rost, M. Leabman, Y. Xiao, A. Mokatrin, H. Koeppen, P.S. Hegde, I. Mellman, D.S. Chen, F.S. Hodi, Predictive correlates of response to the anti-PD-L1 antibody MPDL3280A in cancer patients, Nature 515(7528) (2014) 563567.

[35] N. Ferrara, K.J. Hillan, W. Novotny, Bevacizumab (Avastin), a humanized anti-VEGF monoclonal antibody for cancer therapy, Biochem Biophys Res Commun 333(2) (2005) 328-35.

[36] R.S. Finn, S. Qin, M. Ikeda, P.R. Galle, M. Ducreux, T.Y. Kim, M. Kudo, V. Breder, P. Merle, A.O. Kaseb, D. Li, W. Verret, D.Z. Xu, S. Hernandez, J. Liu, C. Huang, S. Mulla, Y. Wang, H.Y. Lim, A.X. Zhu, A.L. Cheng, Atezolizumab plus Bevacizumab in Unresectable Hepatocellular Carcinoma, N Engl J Med 382(20) (2020) 1894-1905.

[37] M.S. Lee, B.Y. Ryoo, C.H. Hsu, K. Numata, S. Stein, W. Verret, S.P. Hack, J. Spahn, B. Liu, H. Abdullah, Y. Wang, A.R. He, K.H. Lee, Atezolizumab with or without bevacizumab in unresectable hepatocellular carcinoma (GO30140): an open-label, multicentre, phase 1b study, Lancet Oncol 21(6) (2020) 808-820.

[38] L. Kulik, H.B. El-Serag, Epidemiology and Management of Hepatocellular Carcinoma, Gastroenterology 156(2) (2019) 477-491.e1.

[39] K. Okuda, T. Ohtsuki, H. Obata, M. Tomimatsu, N. Okazaki, H. Hasegawa, Y. Nakajima, K. Ohnishi, Natural history of hepatocellular carcinoma and prognosis in relation to treatment. Study of 850 patients, Cancer 56(4) (1985) 918-28.

[40] P.H. Liu, C.Y. Hsu, C.Y. Hsia, Y.H. Lee, C.W. Su, Y.H. Huang, F.Y. Lee, H.C. Lin, T.I. Huo, Prognosis of hepatocellular carcinoma: Assessment of eleven staging systems, J Hepatol 64(3) (2016) 601-8.

[41] A new prognostic system for hepatocellular carcinoma: a retrospective study of 435 patients: the Cancer of the Liver Italian Program (CLIP) investigators, Hepatology 28(3) (1998) 751-5.

[42] EASL, Clinical Practice Guidelines: Management of hepatocellular carcinoma, Journal of Hepatology 69(1) (2019) 182-236.

[43] EASL, EASL-EORTC Clinical Practice Guidelines: Management of hepatocellular carcinoma, Journal of Hepatology 56 (2012) 908-943.

[44] Q. Ye, S. Ling, S. Zheng, X. Xu, Liquid biopsy in hepatocellular carcinoma: circulating tumor cells and circulating tumor DNA, Mol Cancer2019.

[45] P. Kuhn, K. Bethel, A fluid biopsy as investigating technology for the fluid phase of solid tumors, Phys Biol 9(1) (2012) 010301.

[46] G. Siravegna, S. Marsoni, S. Siena, A. Bardelli, Integrating liquid biopsies into the management of cancer, Nat Rev Clin Oncol 14(9) (2017) 531-548.

[47] L. Keller, K. Pantel, Unravelling tumour heterogeneity by single-cell profiling of circulating tumour cells, Nature Reviews Cancer 19(10) (2019) 553-567.

[48] P. Mandel, P. Metais, Les acides nucléiques du plasma sanguin chez l'homme, Comptes rendus de l'Académie des Sciences 142 (1948) 241-243.

[49] M. van der Vaart, P.J. Pretorius, The origin of circulating free DNA, Clin Chem, England, 2007, p. 2215.

[50] H. Schwarzenbach, D.S. Hoon, K. Pantel, Cell-free nucleic acids as biomarkers in cancer patients, Nat Rev Cancer 11(6) (2011) 426-37.

[51] P. Jiang, K.C.A. Chan, Y.M.D. Lo, Liver-derived cell-free nucleic acids in plasma: Biology and applications in liquid biopsies, J Hepatol 71(2) (2019) 409-421.

[52] Z. Huang, D. Hua, Y. Hu, Z. Cheng, X. Zhou, Q. Xie, Q. Wang, F. Wang, X. Du, Y. Zeng, Quantitation of plasma circulating DNA using quantitative PCR for the detection of hepatocellular carcinoma, Pathol Oncol Res 18(2) (2012) 271-6. 
[53] M. Piciocchi, R. Cardin, A. Vitale, V. Vanin, A. Giacomin, C. Pozzan, G. Maddalo, U. Cillo, M. Guido, F. Farinati, Circulating free DNA in the progression of liver damage to hepatocellular carcinoma, Hepatol Int 7(4) (2013) 1050-7.

[54] C.R. Oh, S.Y. Kong, H.S. Im, H.J. Kim, M.K. Kim, K.A. Yoon, E.H. Cho, J.H. Jang, J. Lee, J. Kang, S.R. Park, B.Y. Ryoo, Genome-wide copy number alteration and VEGFA amplification of circulating cell-free DNA as a biomarker in advanced hepatocellular carcinoma patients treated with Sorafenib, BMC Cancer 19(1) (2019) 292.

[55] S. Park, E.J. Lee, C.H. Rim, J. Seong, Plasma Cell-Free DNA as a Predictive Marker after Radiotherapy for Hepatocellular Carcinoma, Yonsei Med J 59(4) (2018) 470-479.

[56] C.K.Y. Ng, G.G. Di Costanzo, N. Tosti, V. Paradiso, M. Coto-Llerena, G. Roscigno, V. Perrina, C. Quintavalle, T. Boldanova, S. Wieland, G. Marino-Marsilia, M. Lanzafame, L. Quagliata, G. Condorelli, M.S. Matter, R. Tortora, M.H. Heim, L.M. Terracciano, S. Piscuoglio, Genetic profiling using plasmaderived cell-free DNA in therapy-naive hepatocellular carcinoma patients: a pilot study, Ann Oncol 29(5) (2018) 1286-1291.

[57] S. Ikeda, I.F. Tsigelny, A. Skjevik Å, Y. Kono, M. Mendler, A. Kuo, J.K. Sicklick, G. Heestand, K.C. Banks, A. Talasaz, R.B. Lanman, S. Lippman, R. Kurzrock, Next - Generation Sequencing of Circulating Tumor DNA Reveals Frequent Alterations in Advanced Hepatocellular Carcinoma, Oncologist2018, pp. 586-93.

[58] Y. An, Y. Guan, Y. Xu, Y. Han, C. Wu, C. Bao, B. Zhou, H. Wang, M. Zhang, W. Liu, L. Qiu, Z. Han, Y. Chen, X. Xia, J. Wang, Z. Liu, W. Huang, X. Yi, J. Huang, The diagnostic and prognostic usage of circulating tumor DNA in operable hepatocellular carcinoma, Am J Transl Res 11(10) (2019) 6462-74.

[59] J. Howell, S.R. Atkinson, D.J. Pinato, S. Knapp, C. Ward, R. Minisini, M.E. Burlone, M. Leutner, M. Pirisi, R. Buttner, S.A. Khan, M. Thursz, M. Odenthal, R. Sharma, Identification of mutations in circulating cell-free tumour DNA as a biomarker in hepatocellular carcinoma, Eur J Cancer 116 (2019) 56-66.

[60] Z. Cai, G. Chen, Y. Zeng, X. Dong, Z. Li, Y. Huang, F. Xin, L. Qiu, H. Xu, W. Zhang, X. Su, X. Liu, J. Liu, Comprehensive Liquid Profiling of Circulating Tumor DNA and Protein Biomarkers in Long-Term Follow-Up Patients with Hepatocellular Carcinoma, Clin Cancer Res 25(17) (2019) 5284-5294.

[61] I. Labgaa, C. Villacorta-Martin, D. D'Avola, A.J. Craig, J. von Felden, S.N. Martins-Filho, D. Sia, A. Stueck, S.C. Ward, M.I. Fiel, M. Mahajan, P. Tabrizian, S.N. Thung, C. Ang, S.L. Friedman, J.M. Llovet, M. Schwartz, A. Villanueva, A pilot study of ultra-deep targeted sequencing of plasma DNA identifies driver mutations in hepatocellular carcinoma, Oncogene 37(27) (2018) 3740-3752.

[62] A.O. Kaseb, N.S. Sanchez, S. Sen, R.K. Kelley, B. Tan, A.G. Bocobo, K.H. Lim, R. Abdel-Wahab, M. Uemura, R.C. Pestana, W. Qiao, L. Xiao, J. Morris, H.M. Amin, M.M. Hassan, A. Rashid, K.C. Banks, R.B. Lanman, A. Talasaz, K.R. Mills-Shaw, B. George, A. Haque, K.P.S. Raghav, R.A. Wolff, J.C. Yao, F. MericBernstam, S. Ikeda, R. Kurzrock, Molecular Profiling of Hepatocellular Carcinoma Using Circulating CellFree DNA, Clin Cancer Res 25(20) (2019) 6107-6118.

[63] R.A. Hlady, X. Zhao, X. Pan, J.D. Yang, F. Ahmed, S.O. Antwi, N.H. Giama, T. Patel, L.R. Roberts, C. Liu, K.D. Robertson, Genome-wide discovery and validation of diagnostic DNA methylation-based biomarkers for hepatocellular cancer detection in circulating cell free DNA, Theranostics 9(24) (2019) 7239-7250.

[64] J. Cai, L. Chen, Z. Zhang, X. Zhang, X. Lu, W. Liu, G. Shi, Y. Ge, P. Gao, Y. Yang, A. Ke, L. Xiao, R. Dong, Y. Zhu, X. Yang, J. Wang, T. Zhu, D. Yang, X. Huang, C. Sui, S. Qiu, F. Shen, H. Sun, W. Zhou, J. Zhou, J. Nie, C. Zeng, E.K. Stroup, B.C. Chiu, W.Y. Lau, C. He, H. Wang, W. Zhang, J. Fan, Genome-wide mapping of 5-hydroxymethylcytosines in circulating cell-free DNA as a non-invasive approach for early detection of hepatocellular carcinoma, Gut 68(12) (2019) 2195-2205.

[65] K.C. Chan, P.B. Lai, T.S. Mok, H.L. Chan, C. Ding, S.W. Yeung, Y.M. Lo, Quantitative analysis of circulating methylated DNA as a biomarker for hepatocellular carcinoma, Clin Chem 54(9) (2008) 152836.

[66] C.Y. Lu, S.Y. Chen, H.L. Peng, P.Y. Kan, W.C. Chang, C.J. Yen, Cell-free methylation markers with diagnostic and prognostic potential in hepatocellular carcinoma, Oncotarget 8(4) (2017) 6406-6418. 
[67] P. Riviere, P.T. Fanta, S. Ikeda, J. Baumgartner, G.M. Heestand, R. Kurzrock, The Mutational Landscape of Gastrointestinal Malignancies as Reflected by Circulating Tumor DNA, Mol Cancer Ther 17(1) (2018) 297-305.

[68] K. Mody, P.M. Kasi, J.D. Yang, P.K. Surapaneni, A. Ritter, A. Roberts, R. Nagy, M.J. Borad, Feasibility of circulating tumor DNA testing in hepatocellular carcinoma, J Gastrointest Oncol 10(4) (2019) 745750.

[69] W. Liao, H. Yang, H. Xu, Y. Wang, P. Ge, J. Ren, W. Xu, X. Lu, X. Sang, S. Zhong, H. Zhang, Y. Mao, Noninvasive detection of tumor-associated mutations from circulating cell-free DNA in hepatocellular carcinoma patients by targeted deep sequencing, Oncotarget 7(26) (2016) 40481-40490.

[70] G. Huang, J.D. Krocker, J.L. Kirk, S.N. Merwat, H. Ju, R.D. Soloway, L.R. Wieck, A. Li, A.O. Okorodudu, J.R. Petersen, N.E. Abdulla, A. Duchini, L. Cicalese, C. Rastellini, P.C. Hu, J. Dong, Evaluation of INK4A promoter methylation using pyrosequencing and circulating cell-free DNA from patients with hepatocellular carcinoma, Clin Chem Lab Med 52(6) (2014) 899-909.

[71] G. He, Y. Chen, C. Zhu, J. Zhou, X. Xie, R. Fei, L. Wei, H. Zhao, H. Chen, H. Zhang, Application of plasma circulating cell-free DNA detection to the molecular diagnosis of hepatocellular carcinoma, Am J TransI Res 11(3) (2019) 1428-1445.

[72] Y. Xiong, C.R. Xie, S. Zhang, J. Chen, Z.Y. Yin, Detection of a novel panel of somatic mutations in plasma cell-free DNA and its diagnostic value in hepatocellular carcinoma, Cancer Manag Res2019, pp. 5745-56.

[73] D. Wang, X. Hu, G. Long, L. Xiao, Z.-M. Wang, L.-D. Zhou, The Clinical Value of Total Plasma CellFree DNA in Hepatitis B Virus-Related Hepatocellular Carcinoma, Annals of Translational Medicine 7(22) (2019).

[74] L. Yan, Y. Chen, J. Zhou, H. Zhao, H. Zhang, G. Wang, Diagnostic value of circulating cell-free DNA levels for hepatocellular carcinoma, Int J Infect Dis 67 (2018) 92-97.

[75] J. Jiao, G.P. Watt, H.L. Stevenson, T.L. Calderone, S.P. Fisher-Hoch, Y. Ye, X. Wu, J.M. Vierling, L. Beretta, Telomerase reverse transcriptase mutations in plasma DNA in patients with hepatocellular carcinoma or cirrhosis: Prevalence and risk factors, Hepatol Commun 2(6) (2018) 718-731.

[76] Q. Xia, Z. Li, J. Zheng, X. Zhang, Y. Di, J. Ding, D. Yu, L. Yan, L. Shen, D. Yan, N. Jia, W. Chen, Y. Feng, J. Wang, Identification of novel biomarkers for hepatocellular carcinoma using transcriptome analysis, Journal of Cellular Phisiology 243(4) (2018) 4851-4863.

[77] R. Mjelle, S.O. Dima, N. Bacalbasa, K. Chawla, A. Sorop, D. Cucu, V. Herlea, P. Sætrom, I. Popescu, Comprehensive transcriptomic analyses of tissue, serum, and serum exosomes from hepatocellular carcinoma patients, BMC Cancer 19 (2019).

[78] X.-J. Lin, Y. Chong, Z.-W. Guo, C. Xie, X.-J. Yang, Q. Zhang, S.-P. Li, Y. Xiong, Y. Yuan, J. Min, W.-H. Jia, Y. Jie, M.-S. Chen, M.-X. Chen, J.-H. Fang, C. Zeng, Y. Zhang, R.-P. Guo, Y. Wu, G. Lin, L. Zheng, S.M. Zhuang, A serum microRNA classifi er for early detection of hepatocellular carcinoma: a multicentre, retrospective, longitudinal biomarker identifi cation study with a nested case-control study, The Lancet Oncology 16(7) (2015) 804-815.

[79] Moustafa Nouh Elemeery, Marwa Anwar Mohamed, Marwa Ahmed Madkour, Mohammed Mohammed Shamseya, Noha Mahmoud Issa, Ahmed Noah Badr, Doaa Ahmed Ghareeb, C.-H. Pan, MicroRNA signature in patients with hepatocellular carcinoma associated with type 2 diabetes, World Journal of Gastroenterology 25(42) (2019) 6322-6341.

[80] S.B. Ghoshal, W.N. Mohd, W. Bo, H. Shu-Hao, D. Jharna, K. Huban, Y. Arti, N. Gerard, K. Pawan, Kalpana, MicroRNA-122 Inhibits Tumorigenic Properties of Hepatocellular Carcinoma Cells and Sensitizes These Cells to Sorafenib, (2009).

[81] D. Bharali, B.D. Banerjee, M. Bharadwaj, S.A. Husain, P. Kar, Expression Analysis of MicroRNA21and MicroRNA-122 in Hepatocellular Carcinoma, Journal of Clinical and Experimental Hepatology 9(3) (2019) 294-301.

[82] J.C. Wischhusen, S.M. Chowdhury, T. Lee, H. Wang, S. Bachawal, R. Devulapally, R. Afjei, U.K. Sukumar, R. Paulmurugan, Ultrasound-mediated delivery of miRNA-122 and anti-microRNA-21 
therapeutically immunomodulates murine hepatocellular carcinoma in vivo, Journal of Controlled Release 321 (2020) 272-284.

[83] Y. An, S. Gao, W.-C. Zhao, B.-A. Qiu, N.-X. Xia, P.-J. Zhang, Z.-P. Fan, Novel Serum microRNAs Panel on the Diagnostic and Prognostic Implications of Hepatocellular Carcinoma, World Journal of Gastroenterology 24(24) (2018) 2596-2604.

[84] Y. Wen, J. Han, J. Chen, J. Dong, Y. Xia, J. Liu, Y. Jiang, J. Dai, J. Lu, G. Jin, J. Han, Q. Wei, H. Shen, B. Sun, Z. Hu, Plasma miRNAs as Early Biomarkers for Detecting Hepatocellular Carcinoma, International Journal of Cancer 137(7) (2015) 1679-1690.

[85] L. Yang, Q. Xu, H. Xie, G. Gu, J. Jiang, Expression of serum miR-218 in hepatocellular carcinoma and its prognostic significance, Clinical Translational Oncology 18 (2016) 841-847.

[86] Y. Zhang, T. Lib, Y. Qiua, T. Zhangc, P. Guoa, X. Maa, Q. Weia, L. Han, Serum microRNA panel for early diagnosis of the onset of hepatocellular carcinoma, Medicine 96(2) (2017).

[87] C. Yang, B.-R. Xia, W.-L. Jin, G. Lou, Circulating tumor cells in precision oncology: clinical applications in liquid biopsy and 3D organoid model, Cancer Cell International 19 (2019) 1-12.

[88] W. Okajima, S. Komatsu, D. Ichikawa, M. Miyamae, T. Ohashi, T. Imamura, J. Kiuchi, K. Nishibeppu, T. Arita, H. Konishi, A. Shiozaki, R. Morimura, H. Ikoma, K. Okamoto, E. Otsuji, Liquid biopsy in patients with hepatocellular carcinoma: Circulating tumor cells and cell-free nucleic acids, World J Gastroenterol 23(31) (2017) 5650-68.

[89] S. Riethdorf, H. Fritsche, V. Müller, T. Rau, C. Schindlbeck, B. Rack, W. Janni, C. Coith, K. Beck, F. Jänicke, S. Jackson, T. Gornet, M. Cristofanilli, K. Pantel, Detection of Circulating Tumor Cells in Peripheral Blood of Patients With Metastatic Breast Cancer: A Vaidation Study of the CellSearch System Clinical Cancer Research 13(3) (2007).

[90] L.-N. Qi, B.-D. Xiang, F.-X. Wu, J.-Z. Ye, J.-H. Zhong, Y.-Y. Wang, Y.-Y. Chen, Z.-C. Chen, L. Ma, J. Chen, W.-F. Gong, Z.-G. Han, Y. Lu, J.-J. Shang, L.-Q. Li, Circulating Tumor Cells Undergoing EMT Provide a Metric for Diagnosis and Prognosis of Patients with Hepatocellular Carcinoma, Cancer Research 79(16) (2018) 4731-4744.

[91] K. Schulze, C. Gasch, K. Staufer, B. Nashan, A.W. Lohse, K. Pantel, S. Riethdorf, H. Wege, Presence of EpCAM-positive circulating tumor cells as biomarker for systemic disease strongly correlates to survival in patients with hepatocellular carcinoma, International Journal of Cancer 133(1) (2013) 21652171.

[92] R.K. Kelley, M.J.M. Magbanua, T.M. Butler, E.A. Collisson, J. Hwang, N. Sidiropoulos, K. Evason, R.M. McWhirter, B. Hameed, E.M. Wayne, F.Y. Yao, A.P. Venook, J.W. Park, Circulating tumor cells in hepatocellular carcinoma: a pilot study of detection, enumeration, and next-generation sequencing in cases and controls BMC Cancer 15 (2015).

[93] W. Xu, L. Cao, L. Chen, J. Li, X.-F. Zhang, H.-H. Qian, X.-Y. Kang, Y. Zhang, J. Liao, L.-H. Shi, Y.-F. Yang, M.-C. Wu, Z.-F. Yin, Isolation of Circulating Tumor Cells in Patients with Hepatocellular Carcinoma Using a Novel Cell Separation Strategy, Clinical Cancer Research 17(11) (2011) 3783-3793. [94] S. Wan, T.H. Kim, K.J. Smith, R. Delaney, G.-S. Park, HuiGuo, E. Lin, T. Plegue, N. Kuo, J. Stefes, C. Leu, D.M. Simeone, N. Razimulava, N.D. Parikh, S. Nagrath, T. H.Welling, New Labyrinth Microfluidic Device Detects Circulating Tumor Cells Expressing Cancer Stem Cell Marker and Circulating Tumor Microemboli in Hepatocellular Carcinoma, Scientific Reports 9(1) (2019).

[95] Z. Wang, L. Luo, Y. Cheng, G. He, B. Peng, Y. Gao, Z.-s. Jiang, M. Pan1, Correlation Between Postoperative Early Recurrence of Hepatocellular Carcinoma and Mesenchymal Circulating Tumor Cells in Peripheral Blood, Journal of Gastrointestinal Surgery 22 (2018) 633-639.

[96] M. Hamaoka, T. Kobayashi, Y. Tanaka, H. Mashima, H. Ohdan, Clinical significance of glypican-3positive circulating tumor cells of hepatocellular carcinoma patients: A prospective study, PLoS One2019.

[97] Y. Ha, T.H. Kim, J.E. Shim, S. Yoon, M.J. Jun, Y.-h. Cho, H.C. Lee, Circulating tumor cells are associated with poor outcomes in early-stage hepatocellular carcinoma: a prospective study, Hepatology International 13 (2019) 726-735. 
[98] J.-j. Yu, W. Xiao1, S.-I. Dong, H.-f. Liang, Z.-w. Zhang, B.-x. Zhang, Z.-y. Huang, Y.-f. Chen, W.-g. Zhang, H.-p. Luo, Q. Chen, X.-p. Chen, Effect of surgical liver resection on circulating tumor cells in patients with hepatocellular carcinoma, BMC Cancer (2018).

[99] Y.-F. Sun, W. Guo, Y. Xu, Y.-H. Shi, Z.-J. Gong, Y. Ji3, M. Du, X. Zhang, B. Hu, A. Huang, G.G. Chen, P.B.S. Lai, Y. Cao, S.-J. Qiu1, J. Zhou, X.-R. Yang, J. Fan, Circulating Tumor Cells from Different Vascular Sites Exhibit Spatial Heterogeneity in Epithelial and Mesenchymal Composition and Distinct Clinical Significance in Hepatocellular Carcinoma, Personalized Medicine and Imaging 24(3) (2018) 547-559. [100] J. Zhang, N. Hao, W. Liu, M. Lu, L. Sun, N. Chen, M. Wu, X. Zhao, B. Xing, W. Sun, F. He, In-depth proteomic analysis of tissue interstitial fluid for hepatocellular carcinoma serum biomarker discovery, British Journal of Cancer 117 (2017) 1676-1684.

[101] A. Macklin, S. Khan, T. Kislinger, Recent advances in mass spectrometry based clinical proteomics: applications to cancer research, Clin Proteomics2020.

[102] L. Yang, W. Rong, T. Xiao, Y. Zhang, B. Xu, Y. Liu, L. Wang, F. Wu, J. Qi, X. Zhao, H. Wang, N. Han, S. Guo, J. Wu, Y. Gao, S. Cheng, Secretory/releasing proteome-based identification of plasma biomarkers in HBV-associated hepatocellular carcinoma, Science China Life Sciences 56(7) (2013) 638646.

[103] T.-H. Tsai, E. Song, R. Zhu, C.D. Poto, M. Wang, Y. Luo, R.S. Varghese, M.G. Tadesse, D.H. Ziada, C.S. Desai, K. Shetty, Y. Mechref, H.W. Ressom, LC-MS/MS-based serum proteomics for identification of candidate biomarkers for hepatocellular carcinoma, Proteomics 15 (2015) 2369-2381.

[104] J. Guo, R. Jing, J.-H. Zhong, X. Dong, Y.-X. Li, Y.-K. Liu, T.-R. Huang, C.-Y. Zhang, Identification of CD14 as a potential biomarker of hepatocellular carcinoma using iTRAQ quantitative proteomics, Oncotarget 8(37) (2017).

[105] Y. Huang, H. Wu, R. Xue, T. Liu, L. Dong, J. Yao, Y. Zhang, X. Shen, Identification of N-Glycosylation in Hepatocellular Carcinoma Patients' Serum with a Comparative Proteomic Approach, PlosONe 8(10) (2013).

[106] H.-J. Gao, Y.-J. Chen, D. Zuo, M.-M. Xiao, Y. Li, H. Guo, N. Zhang, R.-B. Chen, Quantitative Proteomic Analysis for High-Throughput Screening of Differential Glycoproteins in Hepatocellular Carcinoma Serum, Cancer Biology \& Medicine 12(3) (2015) 246-254.

[107] S.J. Yu, H. Kim, H. Min, A. Sohn, Y.Y. Cho, J.-J. Yoo, D.H. Lee, E.J. Cho, J.-H. Lee, J. Gim, T. Park, Y.J. Kim, C.Y. Kim, J.-H. Yoon, Y. Kim, Targeted Proteomics Predicts a Sustained Complete-Response after Transarterial Chemoembolization and Clinical Outcomes in Patients with Hepatocellular Carcinoma: A prospective Cohort Study, Journal of Proteome Research 16 (2017) 1239-1248.

[108] H. Liu, H. Chen, X. Wu, Y. Sun, Y. Wang, Y. Zeng, G. Chen, X. Liu, X. Xing, B. Zhao, J. Liu, The serum proteomics tracking of hepatocellular carcinoma early recurrence following radical resection, Cancer Management and Research 11 (2019) 2935-2946.

[109] S. Shen, H. Peng, Y. Wang, M. Xu, M. Lin, X. Xie, B. Peng, M. Kuang, Screening for immunepotentiating antigens from hepatocellular carcinoma patients after radiofrequency ablation by serum proteomic analysis, BMC Cancer 18 (2018) 1-8.

[110] P. Singh, S. Toom, A. Avula, V. Kumar, O.E. Rahma, The immune modulation effect of locoregional therapies and its potential synergy with immunotherapy in hepatocellular carcinoma, Journal of hepatocellular carcinoma 10(7) (2020) 11-17.

[111] J. Choi, G.A. Kim, S. Han, W. Lee, S. Chun, Y.S. Lim, Longitudinal Assessment of Three Serum Biomarkers to Detect Very Early-Stage Hepatocellular Carcinoma, Hepatology 69(5) (2019) 1983-1994. [112] Q.F. Qin, J. Weng, G.X. Xu, C.M. Chen, C.K. Jia, Combination of serum tumor markers dickkopf-1, DCP and AFP for the diagnosis of primary hepatocellular carcinoma, Asian Pac J Trop Med 10(4) (2017) 409-413.

[113] E.S. Jang, S.H. Jeong, J.W. Kim, Y.S. Choi, P. Leissner, C. Brechot, Diagnostic Performance of Alpha-Fetoprotein, Protein Induced by Vitamin K Absence, Osteopontin, Dickkopf-1 and Its Combinations for Hepatocellular Carcinoma, PLoS One 11(3) (2016) e0151069. 
[114] F. Ding, K. Sun, N. Sun, Q. Jiang, M. Cao, Z. Wu, iTRAQ-based proteomics reveals SOD2 as a potential salivary biomarker in liver cancer, The International Journal of Biological Markers 34(3) (2019) 221-231.

[115] X.Y. You, J. Jiang, F.Z. Yin, K.-H. RUan, Highly sensitive sandwich enzyme immunoassay for alphafetoprotein in human saliva, Annals of Clinical Biochemistry 29 (1993) 519-522.

[116] H. Peng, Z. Yan, X. Zeng, S. Zhang, H. Jiang, H. Huang, H. Zhuo, Serum and tissue proteomic signature of patients with hepatocellular carcinoma using 2-D gel electrophoresis, Molecular Medicine Reports 20(2) (2019).

[117] X. Sheng, T. Huang, J. Qin, L. Yang, Z.-Q. Sa, Q. Li, Identification of the Differential Expression Profiles of Serum and Tissue Proteins During Rat Hepatocarcinogenesis, Technology in Cancer Research \& Treatment 17 (2018) 1-13.

[118] Y. Sun, Z. Zang, X. Xu, Z. Zhang, L. Zhong, W. Zan, Y. Zhao, L. Sun, Differential Proteomics Identification of HSP9O as Potential Serum Biomarker in Hepatocellular Carcinoma by Twodimensional Electrophoresis and Mass Spectrometry, INternational Journal of Molecular Sciences 11 (2010).

[119] W.-W. Wang, S.F. Ang, R. Kumar, C. Heah, A. Utama, N.P. Tania, H. Li, S.H. Tan, D. Poo, S.P. Choo, W.C. Chow, C.K. Tan, H.C. Toh, Identification of Serum Monocyte Chemoattractant Protein-1 and Prolactin as Potential Tumor Markers in Hepatocellular Carcinoma, Plos One 8(7) (2013).

[120] E.-J. Lee, S.-H. Yang, K.-J. Kim, H. Ch, S.J. Lee, J.-H. Kim, J. Song, K.-H. Chun, J. Seong, Inter-alpha Inhibitor $\mathrm{H} 4$ as a Potential Biomarker Predicting the Treatment Outcomes in Patient with Hepatocellular Carcinoma, Cancer Research and Treatment 50(3) (2018) 646-657.

[121] D.J. Kim, E.J. Cho, K.S. Yu, I.J. Jang, J.H. Yoon, T. Park, J.Y. Cho, Comprehensive Metabolomic Search for Biomarkers to Differentiate Early Stage Hepatocellular Carcinoma from Cirrhosis, Cancers (Basel) 11(10) (2019).

[122] D.J. Kim, E.J. Cho, K.-S. Yu, I.-J. Jang, J.-H. Yoon, T. Park, J.-Y. Cho, Comprehensive Metabolomic Search for Biomarkers to Differentiate Early Stage Hepatocellular Carcinoma from Cirrhosis, Cancers 11(10) (2019) 1497.

[123] C. Di Poto, A. Ferrarini, Y. Zhao, R.S. Varghese, C. Tu, Y. Zuo, M. Wang, M.R. Nezami Ranjbar, Y. Luo, C. Zhang, C.S. Desai, K. Shetty, M.G. Tadesse, H.W. Ressom, Metabolomic Characterization of Hepatocellular Carcinoma in Patients with Liver Cirrhosis for Biomarker Discovery, Cancer Epidemiol Biomarkers Prev 26(5) (2017) 675-683.

[124] R. Gao, J. Cheng, C. Fan, X. Shi, Y. Cao, B. Sun, H. Ding, C. Hu, F. Dong, X. Yan, Serum Metabolomics to Identify the Liver Disease-Specific Biomarkers for the Progression of Hepatitis to Hepatocellular Carcinoma, Sci Rep 5 (2015) 18175.

[125] T. Kimhofer, H. Fye, S. Taylor-Robinson, M. Thursz, E. Holmes, Proteomic and metabonomic biomarkers for hepatocellular carcinoma: a comprehensive review, Br J Cancer 112(7) (2015) 1141-56. [126] R. Xu, A. Rai, M. Chen, W. Suwakulsiri, D.W. Greening, R.J. Simpson, Extracelluloar vesicles in cancer - implication for future improvements in cancer care, Nature Reviews Clinical Oncology 15 (2018) 617-638.

[127] R. Chen, X. Xu, Y. Tao, Z. Qian, Y. Yu, Exosomes in hepatocellular carcinoma: a new horizon, Cell Communication and Signalling 17(1) (2019).

[128] X. Zhao, Y. Wu, J. Duan, Y. Ma, Z. She, L. Wei, X. Cui, J. Zhang, Y. Xie, J. Liu, Quantitative Proteomic Analysis of Exosome Protein Content Changes Induced by Hepatitis B Virus in Huh-7 Cells Using SILAC Labeling and LC-MS/MS, Journal of Proteome Research 13 (2014) 5391-5402.

[129] M. Shi, Y. Jiang, L. Yang, S. Yan, Y.-G. Wang, X.-J. Lu, Decreased levels of serum exosomal miR638 predict poor prognosis in hepatocellular carcinoma, Journal of Cellular Biochemistry 119(6) (2017) 4711-4716.

[130] W. Sohn, J. Kim, S.H. Kang, S.R. Yang, J.-Y. Cho, H.C. Cho, S.G. Shim, Y.-H. Paikv, Serum exosomal microRNAs as novel biomarkers for hepatocellular carcinoma, Experimental \& Molecular Medicine 47 (2015). 
[131] A.A.E. Gwad, M. Matboli, A. El - Tawdi, E.K. Habib, H. Shehata, D. Ibrahim, F. Tash, Role of exosomal competing endogenous RNA in patients with hepatocellular carcinoma, Journal of Cellualr Biochemistry 119(10) (2018) 8600-8610.

[132] L. Sun, Y. Su, X. Liu, M. Xu, X. Chen, Y. Zhu, Z. Guo, T. Ba, L. Dong, C. Wei, X. Cai, B. He, Y. Pan, H. Sun, S. Wang, Serum and exosome long non coding RNAs as potential biomarkers for hepatocellular carcinoma, Journal of Cancer 9(15) (2018) 2631-2639.

[133] C. Zhang, X. Yang, Q. Qi, Y. Gao, Q. Wei, S. Han, IncRNA-HEIH in serum and exosomes as potential biomarkers in the HCV-related hepatocellular carcinoma, Cancer Biomarkers 21(3) (2018).

[134] X. Huang, L. Sun, S. Wen, D. Deng, F. Wan, X. He, L. Tian, L. Liang, C. Wei, K. Gao, Q. Fu, Y. Li, J. Jiang, R. Zhai, M. He, RNA sequencing of plasma exosomes revealed novel functional IncRNAs in hepatocellular carcinoma, Cancer Science 7 (2020).

[135] K. Sugimachi, T. Matsumura1, H. Hirata, R. Uchi, M. Ueda, H. Ueo, Y. Shinden, T. Iguchi, H. Eguchi, K. Shirabe, T. Ochiya, Y. Maehara, K. Mimor, Identification of a bona fied microRNA biomarker in serum exosomes that predicts hepatocellular carcinoma recurrence after liver transplantation, British Journal of Cancer 112 (2015) 532-538.

[136] W. Liu, J. Hu, K. Zhou, F. Chen, Z. Wang, B. Liao, Z. Dai, Y. Cao, J. Fan, J. Zhou, Serum exosomal miR-125b is a novel prognostic marker for hepatocellular carcinoma, OncoTargets and Therapy 10 (2017) 3843-3851.

[137] H. Xu, X. Dong, Y. Chen, X. Wang, Serum exosomal hnRNPH1 mRNA as a novel marker for hepatocellular carcinoma, Clinical Chemistry and Laboratory Medicine 56(3) (2017) 479-484. 